IZA DP No. 8224

The Market for Mules:

Risk and Compensation of Cross-Border Drug Couriers

David Bjerk

Caleb Mason

May 2014 


\title{
The Market for Mules: Risk and Compensation of Cross-Border Drug Couriers
}

\author{
David Bjerk \\ Claremont McKenna College \\ and IZA \\ Caleb Mason \\ Miller Barondess, LLP
}

Discussion Paper No. 8224
May 2014

IZA

P.O. Box 7240

53072 Bonn

Germany

Phone: +49-228-3894-0

Fax: +49-228-3894-180

E-mail: iza@iza.org

\begin{abstract}
Any opinions expressed here are those of the author(s) and not those of IZA. Research published in this series may include views on policy, but the institute itself takes no institutional policy positions. The IZA research network is committed to the IZA Guiding Principles of Research Integrity.

The Institute for the Study of Labor (IZA) in Bonn is a local and virtual international research center and a place of communication between science, politics and business. IZA is an independent nonprofit organization supported by Deutsche Post Foundation. The center is associated with the University of Bonn and offers a stimulating research environment through its international network, workshops and conferences, data service, project support, research visits and doctoral program. IZA engages in (i) original and internationally competitive research in all fields of labor economics, (ii) development of policy concepts, and (iii) dissemination of research results and concepts to the interested public.
\end{abstract}

IZA Discussion Papers often represent preliminary work and are circulated to encourage discussion. Citation of such a paper should account for its provisional character. A revised version may be available directly from the author. 


\section{ABSTRACT}

\section{The Market for Mules: Risk and Compensation of Cross-Border Drug Couriers*}

This paper uses a unique dataset to examine the economics of cross-border drug smuggling. Our results reveal that loads are generally quite large (median $30 \mathrm{~kg}$ ), but with substantial variance within and across drug types. Males and females, as well as U.S. citizens and nonU.S. citizens are all well represented among mules. We also find that mule compensation is substantial (median \$1,313), and varies with load characteristics. Specifically, for mules caught with cocaine and meth, pay appears to be strongly correlated to expected sentence if caught, while pay appears to be primarily correlated with load size for marijuana mules, who generally smuggle much larger loads than those smuggling cocaine and meth. We argue that our results suggest that this underground labor market generally acts like a competitive labor market, where a risk-sensitive, reasonably well-informed, and relatively elastic labor force is compensated for higher risk tasks.

\section{NON-TECHNICAL SUMMARY}

This paper provides some of the first estimates of how much cross-border drug smugglers are paid. Moreover, we also find evidence that compensation for drug smuggling responds to sentencing risk, suggesting that this underground labor market can potentially be understood a subject to competitive market pressures, with risk-sensitive, reasonably informed workers being compensated for higher risks. Moreover, our results suggest that border enforcement and sentencing may impact the drug market not just through restricting the amount of drugs that come through the border, but by raising the price due to higher labor costs.

JEL Classification: K42

Keywords: $\quad$ illegal markets, compensating wage differentials, drug smuggling, sentencing

Corresponding author:

David Bjerk

Robert Day School of Economics and Finance

Claremont McKenna College

500 E. Ninth Street

Claremont, CA 91711-6400

USA

E-mail: david.bjerk@cmc.edu

Thanks to Shawn Bushway, Jonathan Caulkins, Peter Reuter, John Pfaff, Eric Helland, and participants at the Conference for Empirical Legal Studies and the University of Houston/Rice Seminar on Applied Empirical Microeconomics for helpful comments and suggestions on this project. 


\section{I - Introduction}

Every year, roughly three thousand people are arrested while working as "mules" smuggling drugs through the ports of entry along the U.S.-Mexico border in California, Arizona, New Mexico, and Texas. For every mule caught, many more get through. Despite the great public concern over cross-border drug smuggling, and the enormous expenditures devoted to stopping it, little is known about this activity. A number of journalistic and scholarly accounts are available (Decker and Chapman 2008; Campbell 2009; Caulkins et al. 2009), but no large-scale empirical analysis of the economics of border smuggling into the United States has been attempted. Yet the economics of border smuggling are vitally important to any assessment of border interdiction and prosecution strategies, and of domestic drug policy.

In this study we analyze a unique dataset extracted directly from the statements of probable cause filed following federal smuggling arrests at California ports-of-entry along the Mexican border to shed light on this underground economy. These statements give the factual details of each smuggling event---time, place, what kind of drug, how much, how it was smuggled, the citizenship of the driver, etc.-- allowing us to thoroughly describe many of the details of drug mules and their cargo along the California- Mexico border.

Additionally, these narratives include information regarding how much money the mule reports being paid, or was promised that he would be paid, for carrying the load. These compensation data provide us with a key variable for analyzing the labor market for mules. While other papers have attempted to look empirically at issues regarding pay for those in the drug distribution business (MacCoun and Reuter 1992; Levitt and Venkatesh 2000), to our knowledge this paper is the first to directly evaluate the extent to which pay responds to sentencing risk. Specifically, all else equal, are mules paid more for carrying loads with higher expected sentencing risk?

This question is of interest not just as a test of economic theory, but also because it may help us better understand how border policing and sentencing policies can interact with the drug market. Specifically, while Reuter and Kleiman (1986) sought to understand how enforcement policy affected the drug market through altering the 
eventual price of drugs to consumers, this study pushes back one step to see how enforcement policy directly affects the cost of getting drugs to the market.

Among the drug mules caught at the California ports of entry, we find that the mean reported compensation amount is $\$ 1,604$ and the median is $\$ 1,313$. Whether this is a lot or a little is a matter of opinion. By way of perspective, at this median wage, drug mules would have to complete a little over two smuggling trips per month to earn the roughly $\$ 35,000$ annual salary paid to American commercial truck drivers with 1 - 4 years of experience (according to payscale.com).

There is also substantial variation in reported pay. While much of this variation is unexplained by the variables we have in our data, pay for mules caught smuggling cocaine and methamphetamine follows a very particular pattern with respect to quantity. Specifically, pay rises initially in quantity quite steeply before leveling off, so that pay hardly varies with load size for mules caught with larger quantities of these two drugs. Quite noticeably, the shape of these pay versus quantity functions are strikingly similar to the shape of the relationship between expected sentence if caught and quantity for these drugs, consistent with the notion that mule compensation for these drugs is at least somewhat tied to sentencing risk if caught.

For marijuana however, while both pay and expected sentence if caught rise monotonically with quantity, the shape of these functions do not match as closely as they do for cocaine and methamphetamine. However, two other things are substantially different for marijuana mules than for cocaine and meth mules. First, marijuana sentences are surprisingly short, averaging well less than two years for even loads approaching 100 kilograms. Second, marijuana loads are generally much larger than loads of cocaine or meth, and there is substantial variation in marijuana load size. Given larger loads, especially of an odorous substance such as marijuana, are more likely to be detected at border crossings, but expected sentence length if caught is relatively limited regardless of quantity, we argue that these findings suggest that compensation for marijuana is tied to expected sentencing risk, but primarily though how load size impacts likelihood of detection rather than through the expected sentence if detected.

Overall, we argue that these findings suggest that the supply of drug mules is sufficiently elastic and that the market is sufficiently developed such that, by in large, 
mules must be compensated for the expected sentencing risk of the load they are smuggling. Using a basic regression specification, our best estimate is that mules are paid on the order of $\$ 1,200$ for an additional year expected sentence if caught (at least for cocaine and methamphetamine smuggling), while an additional 50 kilogram of marijuana translates into roughly $\$ 420$ in additional pay.

Finally, we do not find evidence linking mule compensation to other obvious characteristics of the mule. For example, both in absolute terms, and conditional on the expected sentence upon being caught with the load and amount and type of drug being carried, there is no statistically significant difference between female and male compensation, or between U.S.-citizen and non-citizen compensation. ${ }^{1}$

\section{II - The Theoretical Relationship Between Mule Pay and Sentence Exposure}

Mule compensation is interesting for several reasons. First, understanding the magnitudes in question is important for understanding who might be getting involved in this activity. Is pay sufficiently low that it is really only the truly desperate who find such work worthwhile, or is pay high enough relative to the local labor markets that it is an attractive option to a broad swath of potential workers?

Second, understanding what is correlated with compensation can tell us something about the workings of an inherently unregulated and illegal labor market. Like Gertler, Shah, and Bertozzi's (2005) study of sex workers in Mexico and Gathmann's (2008) study of migrant smugglers in Mexico, we are interested in whether standard models of competitive markets are applicable to illegal underground markets such as this.

Basic economic theory suggests that even in the absence of regulation, a competitive labor market should mean that workers are generally cognizant of the actual risks they take on in performing a particular job, and those taking on an objectively higher risk of a negative outcome should earn a higher wage, all else equal---i.e., a compensating wage differential should arise (Rosen 1986). The labor market for mules offers a test of this theory because while the actual incarceration risk of carrying different loads across the border will depend on load characteristics (type of drug, quantity), the

\footnotetext{
${ }^{1}$ All the mules were either U.S. citizens (45\%) or Mexican citizens (55\%).
} 
labor involved (driving the car across) will not. Our data allow us to examine whether differences in sentencing risk across loads do in fact translate into compensating pay differentials.

While economic theory predicts that compensating wage differentials will arise in a context such as this, we can identify a few plausible reasons why they might not.

First, it is possible that the labor market for drug mules may be "thin," with little systematic organization, causing compensation to be determined on a case-by-case basis. Under this model, mule pay would primarily be determined by the particular interactions and negotiations between a given mule and recruiter, and we would not necessarily expect a strong systematic relationship between compensation and the nature of the cargo as would arise in a more competitive setting.

A second possibility is that the cartels are able to utilize such a desperate labor pool of potential mules that they can simply offer a minimal fixed rate per load. In other words, labor supply to the mule market might be almost perfectly inelastic. Under this model, the mules may care very much about differential sentencing risk, but their concern will not be reflected in compensation because of their more primary concern of obtaining paying work. Indeed, mules may be sufficiently desperate that they do not even demand to be informed about the exact nature of what they are carrying. ${ }^{2}$

Finally, it may be that the likelihood of being caught carrying drug cargo through border crossings is sufficiently small that mules do not have a meaningful incentive to care about what they are carrying. Under this model, the labor market for mules would operate much like the market for couriers of legal goods, with pay simply compensating the mule for his or her time and labor, without variation based on cargo type. Or, compensation may reflect other things, like a fixed percentage of load value.

While it is very difficult if not impossible to precisely ascertain mules' actual risk of being caught bringing in a load of drugs, available evidence does suggest that being caught is quite unlikely. In particular, a rough "back of the envelope" type calculation suggests it is on the order of 5-10\% (see Appendix I). Given such a low chance of

\footnotetext{
${ }^{2}$ The claim of ignorance of cargo is commonly made by the defense in smuggling cases. See for example, United States v. Sepulveda-Barraza, 645F.3d 1066 ( $9^{\text {th }}$ Cir. 2011); Gomez-Granillo v. Holder, 654 F.3d 826 $\left(9^{\text {th }}\right.$ Cir. 2011); United States v. Cordoba, 104 F.3d 225 ( $9^{\text {th }}$ Cir. 1997); United States v. Mendoza, 121 F.3d $510\left(9^{\text {th }}\right.$ Cir. 1997); United States v. Beltran-Lopez, No. $95-50104$ ( $9^{\text {th }}$ Cir. 1995),
} 
detection, it is certainly possible that the large differences in sentence risk by size of load and type of drug are sufficiently discounted that they do not translate into any notable differences in compensation.

In general, while one could argue that markets in the drug trade should generally work according to the standard models of economic theory, as it is essentially a market for semi-refined agricultural crops (or easily manufactured chemicals in the case of meth), sold and transported by an easily substitutable low-skilled labor force, those researchers who have examined this market for many years have often found numerous market irregularities and puzzles (see for example Caulkins and Reuter 2006; Caulkins and MacCoun 2003).

The extent to which changes in sentencing risk produce compensating wage differentials in the market for mules is an interesting question in its own right. On a purely academic level, this market provides an interesting and understudied environment to examine the implications of economic theory---much in the spirit of Levitt and Vankatesh's (2000) analysis of a Chicago street gang's finances, Gertler, Shah, and Bertozzi's (2005) analysis of the sex trade market in Mexico, and Gathmann's (2008) study of the market for migrant smuggling across the Mexico-U.S. border. It is also a first step in comparing the compensation structures in different segments of the underground drug economy: for example comparing the labor market for couriers and the labor market for retail dealers as modeled by Reuter (1990).

Second, there are important policy implications. The United States spends large sums of money detecting, prosecuting and incarcerating individuals caught transporting drugs through its borders. It is therefore it is important to analyze the effect such enforcement policies have on the economics of the illegal drug importation industry. Specifically, if cartels generally do not have to compensate mules (or compensate them much) for the extra incarceration risk they incur for smuggling different types and sizes of drug loads, then border policing and incarceration policy would have little effect on the supply of willing mules and thus on the bottom line of the cartels. On the other hand, if cartels do in fact generally have to compensate mules for the differential incarceration risk associated with different loads, then we can infer that detection and sentencing 
policies do affect cartel labor costs, and thus, the profits for cartels (at least to some extent).

\section{III - Description of Data}

The data used for our analysis are collected directly from the statements of probable cause filed in every federal border-smuggling case, or "border bust." Our study examines the busts made at California ports of entry from the latter half of 2006 through 2010.

To describe where this data comes from, it will be helpful to describe the typical way in which a border bust proceeds. People wishing to cross through a port of entry from Mexico to the United States (either by car or on foot) go through three stages of inspection: pre-primary (lining up to get to the inspection booth), primary (presentation of documents at the inspection booth), and secondary (intensive inspection if referred from primary). The physical border line is south of the inspection booths, so as cars line up and wait they are already in the United States, and inspection, usually dog sweeps, may occur there. At pre-primary, as cars line up, officers walk with drug-sniffing dogs in random sweeps through the lanes. If a dog alerts to a vehicle, the vehicle is immediately sent to secondary inspection, where the car will be more closely inspected.

Officers may also refer a vehicle to secondary after the primary inspection at the booth. These referrals may be because of the driver's demeanor, or responses, or documents. They may also be based on tips from informants, or they may be purely random (at random intervals, the computer system will direct inspectors to refer cars to secondary).

When a vehicle is referred to secondary, the officers will remove the driver from the vehicle and take him or her inside the station while the secondary inspection is conducted. If hidden packages are found, they are removed and weighed, and the contents field-tested for the presence of illegal drugs.

Whenever concealed loads of drugs are discovered, the customs officers contact Immigration and Customs Enforcement (ICE) agents, who take over the case and interview the suspects. The probable cause statements we use for this study are drafted by the responding ICE agents and then filed with the court when the suspects are charged. 
To obtain these probable cause statements, we first used Westlaw to identify drug importation cases charged in the Southern District of California. We then used the PACER system (Public Access to Court Electronic Records) maintained by the federal judiciary to access the docket filings for each case. For each case, we accessed the docket, then downloaded a pdf image of the complaint and probably cause statement, from which we obtained our data.

From these statements of probable cause we obtain our key variables of drug type, drug amount, and reported compensation. Furthermore, we also coded several other variables including time, date, and day of the week of the bust, interview response (e.g., confessed to the charges/denied the charges/invoked right to silence), type of identification presented, citizenship, and gender. Finally, we were able to also use the case dockets to obtain data on the outcome of each case and the actual sentence imposed. ${ }^{3}$

We classified citizenship based on what could be inferred from the type of identification presented, with U.S. passports and birth certificates being coded as U.S. citizens and visas of any kind (mostly I-551s (legal permanent resident visas) or B1/B2s (Border Crossing Cards) coded as non-U.S. citizens.. ${ }^{4}$

We excluded any cases in which 21 U.S.C. 952, the importation offense, was charged for personal-use amounts (e.g., less than half a kilogram). We also excluded cases in which Section 952 was charged as part of a broader conspiracy in which there was not a specific smuggling event within our time range recorded in the complaint, and we excluded cases that were not port-of-entry cases (e.g., stash house, tunnel, boat or plane cases) as they seemed to be of a fundamentally different nature.

Sixty-four percent of the suspects in our dataset confess to smuggling at the time of arrest. Of these, seventy-nine percent provide information regarding their

\footnotetext{
${ }^{3}$ Some sentences are reported as "time served," and we translated these into months by calculating from the docket the total amount of time between arrest and judgment, subtracting any time out on bail. And many marijuana sentences are probation. Rather than code these as if no time were spent behind bars, we calculated from the dockets the amount of time spent incarcerated prior to imposition of the sentence. We employed the same method for dismissals and acquittals: we code them based on the amount of time incarcerated prior to judgment.

${ }^{4}$ When the identification presented was a state i.d. or driver's license, we coded citizenship as U.S., because all foreign citizens have always had to present immigration documents, while prior to 2009, U.S. citizens could enter with a state i.d. or driver's license. (Since 2009, U.S. citizens have had to present passports.) In some cases, the report simply stated the defendant's citizenship, which we coded accordingly.
} 
compensation or promised compensation. ${ }^{5}$ In total, we have pay information available for fifty-one percent of our observations. We converted all payment amounts to 2010 dollars using the Consumer Price Index.

One obvious concern about this data is the reliability of the defendants' answers regarding their pay, or promised pay, as there is no direct way to verify whether they are telling the truth. Given that punishment is not affected by what a mule reports regarding his pay or promised pay, there is no objective incentive for any defendant to over-report, under-report, or conceal his promised pay once he has made the initial decision to confess. However, one can think of reasons why captured mules may still mis-report. For example, they may not believe their punishment is unaffected by what they report, or they may believe their interrogators may try to solicit bribes if higher pay is reported (one could imagine this to be a consideration for Mexican mules who may have had interactions with corrupt law-enforcement officials). On the other hand, a mule might overstate his true pay in an attempt to aggrandize his role in the operation, perhaps to make himself appear a better candidate for a cooperation deal.

To the extent there is mis-reporting, and if this mis-reporting is more often one way than the other, this could potentially bias our results. Or, if such mis-reporting leads to classical measurement error, such mis-reporting might simply cause our results to be too imprecise to be informative. The results below suggest the latter is not too large an issue. Regarding potential bias, there is not a whole lot we can say with certainty. However, our data suggests that it is unlikely that Mexican mules systematically underreport their pay relative to U.S. mules because of a fear of official solicitation of bribes. In particular, if this were true, then we would see higher reported wages, controlling for other factors, for U.S.-citizen mules than for Mexican-citizen mules. But, as we show later, mule citizenship actually has no significant relationship to reported pay.

\footnotetext{
${ }^{5}$ When payment was in pesos, we converted to dollars. In a handful of cases, the payment was the car itself or a certain amount of the drugs. In those cases we used the Kelly Blue Book value for the year, make and model of car, using the "private party sale" figure for a car in "good" condition and 50,000 miles. When payment was in drugs, we used regional retail Office of National Drug Control Policy (ONDCP 2007) price data to convert to dollars. However, these types of non-cash payments were less than $10 \%$ of the cases for which we have compensation data.
} 
Because our data is from federal prosecutions, we do not have complaints for cases that were prosecuted instead by state authorities. While this is certainly an issue for further study, for reasons we discuss in Appendix II, we do not think it undermines the validity of our results here.

Looking at the data, we see that load sizes are generally quite large, with a mean size of 60 kilograms. However, there is substantial variation. The median load size is 30 kilograms, while the $90^{\text {th }}$ and $10^{\text {th }}$ percentiles are 77 kilograms and 6 kilograms respectively. Not surprisingly, there is substantial variation in load size by drug type. Table 1 gives information about the distribution of load sizes by drug type for the three common drug types. ${ }^{6}$ Notably, methamphetamine (median $8 \mathrm{~kg}$ ) loads are generally much smaller than cocaine loads (median $22 \mathrm{~kg}$ ), and marijuana (median $42 \mathrm{~kg}$ ) loads are generally much larger than cocaine. Specifically, while the $90^{\text {th }}$ and $10^{\text {th }}$ percentiles of the cocaine loads are 36 kilograms and 6 kilograms respectively, the analogous measures for marijuana loads are 102 and 18 kilograms respectively.

Figure 1 shows histograms of the quantity distribution by drug type. As can be seen graphically, mules were caught with load sizes that spread relatively evenly across the distribution. The one noticeable spike is with respect to very small loads of meth. In particular, we see a disproportionate number of loads just below $0.5 \mathrm{~kg}$. This is notable, as $0.5 \mathrm{~kg}$ is the cutoff amount that determines eligibility for a 10 year mandatory minimum sentence for meth. It is worth noting however, that there are also mandatory minimum cutoff quantities for cocaine at $0.5 \mathrm{~kg}$ and $5 \mathrm{~kg}$, and a mandatory minimum cutoff quantity for marijuana at $100 \mathrm{~kg}$, yet we see little evidence of "bunching" just below these cutoffs. We will return to this issue below.

In terms of demographics of the mules, we find that little under one quarter of the apprehended mules were female, with this fraction was relatively constant by type of drug smuggled ( 0.20 for cocaine, 0.25 for meth, and 0.22 for marijuana). Similarly, a little under fifty percent of apprehended mules are U.S. citizens, with again this fraction being roughly constant across drug types ( 0.31 for cocaine, 0.49 for meth, 0.45 for marijuana).

\footnotetext{
${ }^{6}$ These three drugs alone account for well over $95 \%$ of the total observations in the data. We feel there are two few observations of the other drugs for meaningful analysis.
} 


\section{IV-Analysis of Mule Compensation}

In analyzing mule compensation, we focus on those carrying only one type of drug through the border. This restriction is not very limiting, however, as fewer than $4 \%$ of our observations were carrying more than one type of drug. Moreover, the group of individuals caught carrying more than one drug is extremely heterogeneous, carrying numerous different combinations of drugs of various sized loads, and in some cases it appears that one of the drugs they are caught with are in quantities that suggest it is for personal use rather than distribution. Therefore, we feel making any statistical inferences from this group would not be warranted.

For those mules arrested carrying only one drug coming through one of the California ports of entry, the mean reported pay is $\$ 1,643$. However, there is substantial variation, as the median of the distribution is $\$ 1,313$, with a tenth percentile of $\$ 505$ and a ninetieth percentile of $\$ 3,030$. Even with a $\$ 1,313$ median, though, this compensation is arguably substantial. As alluded to in the introduction, the website payscale.com reports that American commercial truck drivers with $1-4$ years of experience earn roughly $\$ 35,000$ per year, meaning at this median amount for mule pay, a mule would only have to make about two trips per month to earn this much money.

Another point of comparison is to compare this median mule earnings amount to measures of average earnings in the border regions. One such measure is the Per Capita Gross Regional Revenue, which is the regional equivalent of Per Capita Gross National Product. Using data for 2000, Anderson and Gerber (2008) report an annual Per Capita GRR for the border counties of the United States to be $\$ 25,067$, which translates to $\$ 32,164$ in 2010 dollars. For the border counties on the Mexico side of the border, Anderson and Gerber (2008) report an annual Per Capita GRR in 2000 to be only $\$ 10,458$, which translates to only $\$ 13,419$ in 2010 dollars. Hence, at the median pay level, a mule will surpass the average annual earnings for other residents of the U.S.Mexico border region in between 10 and 20 trips over the course of a year. This is arguably quite high pay given the relatively small amount of specific skill required.

Pay also appears to differ substantially by type of load. As can be seen in the top panel of Table 2, mules carrying cocaine loads generally appear to be paid the most, followed by mules carrying meth loads, with mules carrying marijuana loads reporting 
pay almost fifty percent less than cocaine mules on average. We will explore such differences in pay across drugs in more depth in the following subsection.

\section{IV(a) - The Relationship Between Compensation and Sentencing Risk}

As discussed above, if pay for mules is at least partly compensating them for expected jail time, then mean pay should respond to both the likelihood of detection and to the expected sentence to be served if caught. In this section we attempt to evaluate these hypotheses.

In doing this analysis we did two types of trimming of the sample. First, we excluded cases in which more than one person was charged with the offense, as in such cases the individuals in these cases were treated very differently during sentencing suggesting different roles played in the operation. Moreover, it wasn't obvious how the reported compensation was actually supposed to be divided between defendants. Second, we had to deal with outliers. Two types of outliers concerned us: quantity outliers and pay outliers. We attempted to deal with both types of outliers as conservatively as possible.

With respect to quantity outliers, as will be seen below, much of what we are interested in is how pay responds to increased expected sentence exposure (i.e., the expected sentence associated with actually being caught) which in turn depends on drug type and quantity. Therefore, in order to make plausible statistical inference, we need multiple observations by drug within a relatively narrow quantity range. This in turn necessitated some trimming of the sample to exclude loads with few or no other observations "nearby." The exclusion rule that we used was to exclude any observation with less than ten other observations with pay data within five kilos. This procedure excluded 11 observations for cocaine, 33 observations for meth, and 93 observations for marijuana. While keeping these outliers in the sample does not change our results dramatically, it does decrease the precision of our estimates, and indeed we would argue that making statistical inference near such observations is likely to be misleading.

The second type of outliers is pay outliers. The concern here is that there might be measurement error in reported pay, and while under-reporting of pay is bounded from below at zero, over-reporting of pay is unbounded. Indeed, we have a couple of pay 
observations that are over 10 standard deviations from the median. To deal with these outliers we do a type of "winsorizing" of the data. Specifically, we first find any observations that have reported pay greater than five standard deviations away from the $90^{\text {th }}$ percentile of that drug. We found two such observations for cocaine, two such observations for marijuana, and zero such observations for meth. We then replace those two extreme pay amounts for cocaine and marijuana, as well as the two smallest pay amounts for cocaine and marijuana, with the third largest and third smallest pay observations for each drug respectively. As discussed by Rivest (1994), such a procedure can lead to large efficiency gains with minimal bias. Again, while our basic results do not change qualitatively when we do not use this procedure, the precision of some of our estimates decreases.

The lower panel of Table 2 summarizes how using this "trimmed" sample alters the pay distribution in the data. As can be seen, our trimming procedures do not lead to large changes in the basic summary statistics.

Let us now consider sentencing risk, and the relationship between pay and sentencing risk. In a standard model of compensating wage differentials, pay should positively correlate with the actual variation in risk. In the context of drug mules, risk is effectively the probability of being caught times the expected sentence associated with being caught. As discussed briefly above, we do not have any direct data on likelihood of being caught, but we think it is likely quite small. However, even if small, it certainly might vary by load, particularly with large variations in the size of load. This is something we will return to again later in the paper.

In terms of the expected sentence if caught---hereafter expected sentence exposure---we are able to measure quite well. There are both federal Sentencing Guidelines and federal mandatory minimum sentencing laws that apply to individuals arrested bringing drugs into the United States. While at first blush this would seem an obvious place to start to determine sentencing risk for different loads, conversations with federal prosecutors in the Southern District of California suggested that these guideline sentences and mandatory minimums are rarely applied for this population of arrestees; rather most of these cases were resolved through the "Safety Valve" statute (18 U.S.C. $\S 3553(\mathrm{f})$ ), which avoids the mandatory minimums for defendants with minimal criminal 
history (i.e. one criminal history point or less), did not use violence or a weapon or cause bodily injury, was not an organizer or leader, and were determined to fully cooperate with investigators. ${ }^{7}$ For this reason, as mentioned previously, we actually went and collected data on the actual sentence received by each individual in our data set from court records.

Table 3 shows the mandatory minimum sentences, the guideline sentence range (which have been advisory since the Booker decision in 2005), and the actual average sentences for each drug/quantity guideline cell. As can be seen, consistent with our conversations with federal prosecutors in the Southern District of California, the vast majority of defendants in our data do not appear to be sentenced according to either the mandatory minimum sentences or even the guidelines. There are really only two ways for a defendant ostensibly eligible for a mandatory minimum sentence to receive a lesser sentence. One is to be determined to have provided "substantial assistance" to the court, or two is to be deemed eligible for the safety valve. As discussed previously, eligibility for the latter is restricted to those with minimal criminal histories. This suggests most of the individuals in our data have minimal criminal histories, but we will return to this issue later in the paper. The other thing to notice is that for meth and cocaine, among the larger load sizes, average sentence length surprisingly does not appear to increase with load size. We examine this issue in more depth below.

The basic results regarding expected sentence exposure and pay can be seen in Figures 2a-2c. These figures essentially show non-parametrically smoothed functions regarding the relationship between sentence length and quantity, and pay and quantity, by drug type. Let us first consider our measure of expected sentence exposure as shown by the dashed lines in each of these figures. These dashed lines are computed by calculating a locally weighted mean sentence length associated with each possible quantity in the range of our data for that drug. Specifically, we use the "lpoly" command in Stata, which estimates a zero degree polynomial functional form with an Epinechnikov weighting kernel. For example, in calculating the expected sentence exposure for a defendant caught with 20 kilos of cocaine, we essentially calculate a weighted mean sentence for defendants with cocaine loads, where those with loads near 20 kilos receive the highest

\footnotetext{
${ }^{7}$ One author, Caleb Mason, was an Assistant US Attorney in the Southern District of California from 20072009.
} 
weight, while those with loads below and above 20 kilos receive progressively less weight in calculating the weighted mean. We feel this procedure will give the most accurate measure possible of the ex ante expected sentence exposure associated with each load.

One thing that is immediately noticeable with respect to these dashed lines in Figures $2 \mathrm{a}$ and $2 \mathrm{~b}$, is that for both cocaine and meth cases, expected sentence exposure rises with load size initially, but quite quickly stops increasing as load size increases. Again, this would not be the case if defendants were generally receiving sentences consistent with the base guideline recommendations, and moreover, expected sentence exposure does not appear to increase at mandatory minimum cutoff quantities. Again, this suggests the guidelines and mandatory minimums are rarely being applied for this population. As can be seen in Figure 2c however, expected sentence exposure is consistently increasing in quantity for marijuana cases throughout the whole range. However, it is also somewhat surprising how short expected sentence exposure actually is for most marijuana loads---almost always less than one year. Overall, we find these results with respect to sentencing quite surprising, as we have seen little direct documentation of actual sentencing outcomes for drug mules caught at border crossings.

Moving on to our analysis of pay, the solid lines in Figures 2a-2c show the locally weighted mean pay amounts associated with each possible quantity in the range of our data for each drug (calculated in the same manner as described above). What is most notable here is that these solid lines in Figures $2 \mathrm{a}$ and $2 \mathrm{~b}$ show that average pay is initially rising in quantities of cocaine and meth smuggled, but quickly levels off. Indeed, these pay functions level off at quite similar quantities to where the expected sentence exposure functions level off. The degree to which these pay and sentencing curves track each other in Figures $2 \mathrm{a}$ and $2 \mathrm{~b}$ are actually very surprising, as there is no mechanical reason for this to be the case, and indeed the data for pay and the data for sentencing were collected from completely different sources.

The results for marijuana in Figure $2 \mathrm{c}$ are a bit different. While the both the expected sentence exposure function and pay function with respect to quantity are quite flat, the pay function is quite a bit steeper at relatively smaller load sizes, while the 
expected sentence exposure function doesn't really start to steepen until large load sizes on the order of $60 \mathrm{~kg}$.

Before discussing how to interpret the results in Figures $2 a-2 c$, it is worth exploring these relationships in a bit more detail. One concern regarding the results discussed above is that they are sensitive to the smoothing specification. Figures $3 a-3 c$ show how things change when we use a first degree locally weighted polynomial to fit the data rather than locally weighted means (i.e., a zero degree locally weighted polynomial). Intuitively, for each quantity for each drug, this procedure estimates a weighted linear regression of sentence length on quantity, where weights are inversely proportional to the distance from that quantity. Presumably, this specification should fit our smoothed function even more closely to the data.

As can be seen in Figures $3 a-3 c$, the basic picture is essentially unchanged from Figures $2 \mathrm{a}-2 \mathrm{c}$. For cocaine and meth cases, the pay functions track the expected sentence exposure functions very well over the quantity range, rising initially then leveling off quite quickly. For marijuana cases, both the pay function and the expected sentence exposure function are quite flat, though pay initially rises more quickly than expected sentence exposure before leveling off.

Overall, these figures show that for cocaine and meth, changes in pay track changes in expected sentence exposure quite closely, suggesting pay for cocaine and meth loads is indeed tied to the expected sentence exposure associated with the load. It is actually surprising how closely these functions track each other. It is also surprising how quickly both level off, meaning smuggling larger loads of cocaine and meth not only do not really increase expected sentence exposure, but they also don't appear to pay any better.

On the other hand, pay for marijuana loads does not seem to very closely track expected sentence exposure. Rather, pay simply appears to rise with load size up to about 35 - 40 kilograms before leveling off. Maybe this should not be surprising however, given that expected sentence exposure is quite low across the quantity range, generally being less than a year and never rising above 1.5 years even for loads greater than $75 \mathrm{~kg}$. However, attempting to smuggle larger and larger loads across the border likely increases detection risk. Therefore, one could argue that the pay gradient with respect to quantity 
for marijuana loads is more closely tied to sentencing risk via changes in detection probabilities rather than changes in expected sentence exposure.

The fact that pay appears to be associated with expected sentence exposure for cocaine and meth, but quantity for marijuana, may partially help explain the load size distributions shown in Figure 1. Specifically, pay initially increases with load size for cocaine and meth as expected sentence exposure increases, but as expected sentence exposure becomes roughly constant quantity so does pay. Hence, there is little reason for a mule to take on much additional quantity of these drugs since it may increase the likelihood of detection but does not increase pay. Hence, the distribution of load size is concentrated to loads below $30 \mathrm{~kg}$ for cocaine and $15 \mathrm{~kg}$ for meth. By contrast, compensation is generally increasing (though at a modest rate) in load size for marijuana mules. Hence, mules looking to make more money can do so by taking on larger loads. This is reflected in the distribution of load sizes for marijuana, which varies substantially more and encompasses a much larger range than cocaine and meth load sizes.

Figures $4 a-4 d$ graphically show the direct relationship between pay and expected sentencing exposure in the pooled sample of all drugs, as well as for each drug separately. These graphs again employ a first degree local polynomial to obtain the smoothed function. The general impression from Figure $4 \mathrm{a}$ is one of pay modestly rising in expected sentence exposure. This simple picture may be somewhat misleading however; as Figures $2 \mathrm{a}-2 \mathrm{c}$ showed, there is very little overlap in expected sentence exposure across drugs. Essentially, almost all the marijuana loads carry expected sentence exposure of 1.5 years or less, while the expected sentence exposure for all of the loads for the other drugs exceeds 2 years. So, the shape of aggregated graph shown in Figure $4 \mathrm{a}$ is actually just connecting the upper envelopes of three very distinct relationships across the different drugs. To accurately understand the relationship between pay and sentencing risk, we must take into account this heterogeneity in sentencing across drug types.

Looking at Figures $4 \mathrm{~b}-4 \mathrm{~d}$ we see that, within drug, pay does appear to be positively and monotonically associated with expected sentence exposure for cocaine and meth, but less so for marijuana. Moreover, conditional on expected sentence exposure, pay differs quite a bit across drugs. For example, for loads associated with around 4 
years in prison if caught, cocaine loads appear to be compensated at over twice the rate of meth loads (a little over $\$ 2,000$ versus roughly $\$ 1,000$ ). Or, just as notably, a marijuana load with an expected sentence exposure of just one year is compensated on average at the same level as a cocaine load with an expected sentence exposure of two and a half years, or a meth load with an expected sentence exposure of four and a half years.

As discussed above, one explanation for this variation is likely related to differences in the likelihood of apprehension. While we are not able to measure the likelihood of getting caught directly, we suspect that the likelihood of getting caught at the border is arguably an increasing function of how much contraband the individual is attempting to smuggle (more contraband would require more or larger hidden compartments, which would presumably be harder to conceal, and would likely have a stronger odor, particularly for marijuana) and the different drugs carry very different expected sentence exposure for similar weights. Looking back at Figures $2 \mathrm{a}-2 \mathrm{c}$, a mule must be carrying almost 20 kilograms of cocaine to have an expected sentence exposure of 4 years, but even the smallest loads of meth incur an expected sentence exposure of 4 years. Contrast both of these to marijuana, where 80 to 100 kilogram loads still have an expected sentence exposure of less than 2 years. Hence, it is not very surprising that marijuana loads pay more than cocaine and meth loads with even slightly longer expected sentence exposure.

We can also use regression analysis to describe the relationships between pay and sentencing risk. In particular, we can use OLS to regress pay on total quantity, total quantity squared, expected sentence exposure, dummies for each type of drug, and a linear monthly time trend. While the non-parametric results in Figures $4 \mathrm{~b}-4 \mathrm{~d}$ reveal that the relationship between pay and expected sentence exposure is not perfectly linear for any of the drugs, they also reveal that the linear approximation associated with OLS will not be dramatically off base. The OLS results can give us a point estimate of the monetary value associated with a marginal year of expected sentence exposure. However, given the pay distribution is right skewed, we also regress the natural log of pay on total quantity, total quantity squared, expected sentence exposure, dummies for each type of drug, and a linear monthly time trend to see if this gives us a better fit. 
Table 4a shows the results when using pay level as the dependant variable, with specification (1) pooling all drugs and estimating separate intercepts for each drug, and specifications (2) - (4) estimating the coefficients on quantity and expected sentence exposure separately for each drug. As can be seen in specification (1), the coefficient on expected sentence exposure is positive and highly statistically significant, confirming pay is positively related to expected sentence exposure even after conditioning on total quantity. Taken at face value, these results suggest that a marginal year of expected sentence exposure is associated with about $\$ 728$ in additional compensation. Moreover, the coefficient on total quantity (in thousands of kilos) is also positive and significant, suggesting that conditional on expected sentence exposure, larger loads received higher compensation (though increasing at a diminishing rate as evidenced by the negative coefficient on total quantity squared). Again, to the extent that larger loads increase likelihood of detection, this finding is also consistent with a compensating wage differential for sentencing risk.

The fact that the coefficients on the drug specific intercepts differ simply reflect what was shown in Figures $4 \mathrm{~b}-4 \mathrm{~d}$, namely that conditional on expected sentence exposure, marijuana loads are paid the most, while meth loads are paid the least. Note that this holds even after controlling for load size. This may potentially reflect the fact that marijuana loads, and to some extent cocaine loads, likely have a stronger odor than meth loads, making them easier for border patrol dogs to detect, all else equal.

Again however, the results in Table 4a may be problematic, as they constrain the coefficient on expected sentence exposure to be the same across drugs, even though Figures $4 \mathrm{~b}-4 \mathrm{~d}$ showed that the strength of the relationship between expected sentence exposure and pay appears to differ strongly between cocaine and meth on the one hand, and marijuana on the other. Therefore, specifications (2) - (4) do the regressions separately by drug. As can be seen, the coefficient on expected sentence exposure is statistically significant in specifications (2) and (3) for cocaine and meth respectively, suggesting that an additional year of expected sentence exposure translates into roughly $\$ 1200$ - \$1400 more in pay for smuggling these drugs. Quantity, on the other hand, does not appear to be positively associated with pay for cocaine and meth mules after controlling for expected sentence exposure. 
By contrast, consistent with the previous figures, the coefficient on expected sentence exposure in specification (4) is smaller in magnitude and statistically insignificant, suggesting greater expected sentence exposure does not really impact pay for marijuana mules after controlling for load size. But, quantity is positively and significantly correlated with pay for marijuana mules even after controlling for expected sentence exposure. The coefficients in specification (4) suggest that increasing load size by 50 kilograms, for example going from the 10th percentile of the marijuana quantity distribution (18 kilograms) to the 90th percentile (68 kilograms) of the "trimmed" sample, will on average increase pay by just under $\$ 420$.

As discussed above, one interpretation of these results is that since even the largest marijuana loads are not punished very harshly (generally less than 2 years expected sentence exposure at most), but quantities tend to be quite large, mules transporting marijuana are more concerned about how changes in load size alter the likelihood of being caught rather than how different load sizes alter the expected length of the sentence they would get if caught. On the other hand, since there is not nearly as large variation in the size of cocaine and meth loads, but there are quite long sentences if caught, mules transporting these drugs may be more concerned about how different load sizes vary the expected length of sentence upon being caught rather than the likelihood of being caught.

Table $4 \mathrm{~b}$ shows the analogous results to Table $4 \mathrm{a}$, but using the natural log of pay as the dependant variable rather than pay level. The log specifications do seem to increase the fit of the regressions substantially for cocaine and meth mules, with the Rsquared increasing from 0.064 to 0.172 for the cocaine specifications and from 0.131 to 0.329 for meth. These latter R-square values are arguably quite large given the fact that effectively all of this explanatory power of these regressions is coming from just the expected sentencing exposure variable. By way of comparison, in a couple of well cited papers in general labor economics literature, Neal and Johnson (1996) only get an Rsquared of 0.16 in a log wage regression that includes race, age, highest grade, and even pre-market test scores as control variables, while O'Neill and Polacheck (1993) get up to an R-squared of 0.32 but only when controlling for region, marital status, schooling, potential experience, occupation, and industry. Hence, at least for drug mules smuggling 
cocaine and meth, expected sentence exposure appears to explain a relatively large amount of the wage variation, which in a way should be expected given the pictures in Figures $2 \mathrm{a}-2 \mathrm{~b}$ and $3 \mathrm{a}-3 \mathrm{~b}$.

By in large, the results shown in Table $4 \mathrm{~b}$ are essentially comparable to those in Table $4 \mathrm{a}$, with the coefficients on expected sentence exposure being positive and statistically significant for cocaine and meth mules, but indistinguishable from zero for marijuana mules. By contrast, after controlling for expected sentence exposure, quantity does not appear to be positively correlated with pay for cocaine and meth mules, but does appear to be positively and significantly correlated with pay for marijuana mules.

\section{IV(b) - Evaluating Other Explanations}

The results discussed above are consistent with a significant wage premium being paid for carrying higher sentencing risk loads. However, another potential hypothesis is that mule compensation is generally determined as a fixed percentage of load value. In particular, since both expected sentence exposure and load value are increasing functions of load size within drug, one might be concerned that the results above are not driven by compensating wage differentials, but rather a load value sharing rule for compensation.

While this is a reasonable concern, and given the common correlation of expected sentence exposure and load value with quantity we cannot definitively rule this story out, Figures 2a-2c suggest to us that this story to be unlikely. In particular, these figures show that pay for cocaine and meth initially increase quite steeply with quantity, but relatively quickly level off, with little variation in average pay for larger loads. While this was shown to correspond very closely to how sentencing seems to work for this population (i.e., rises substantially with quantity initially before leveling off with little variation in average sentence length among higher load sizes), it is hard to see why this would happen if pay was primarily tied to load value. While it is notoriously hard to have good estimates of values of different quantities of different drugs, one would not think the general shape of the load value functions would track very closely with shapes of the expected sentence exposure functions as shown in Figures $2 \mathrm{a}$ and $2 \mathrm{~b}$.

Indeed, arguably the best estimates of how drug values vary by quantity comes from the Caulkins and Padman (1993) and Caulkins et al. (2009) model describing drug 
pricing according to a power law: $\mathrm{P}(\mathrm{Q})=\alpha \mathrm{Q}^{\beta}$. Specifically, if drugs are marked up by $100(\delta-1) \%$ as they move through each transaction layer with a branching factor of $\varphi$, then to price of a transaction of quantity $Q$ will be captured by the equation $P(Q)=\alpha Q^{\beta}$, where $\beta=1-\ln (\delta) / \ln (\varphi)$. To estimate drug values for observations in our data using this model, we used a different parameterization for each drug where the $\beta$ values were taken from the "mid-level" estimates from the U.S. drug market in Arkes et al. (2004) via Table 3 from Caulkins et al. (2009) ( $\beta$ values for meth were not available so we cannot calculate value estimates for these loads). We then used the "mid-level" prices per ounce of each drug as stated in the National Illicit Drug Prices report put out by the U.S. Department of Justice (USDOJ 2008) and the $\beta$ 's discussed above to back out the implied value for $\alpha$ associated with each drug. ${ }^{8}$ Once we know $\alpha$ and $\beta$ for each drug, we can then calculate a load value for each cocaine and marijuana load in our data set given its type and quantity.

While the power law of value described above does imply that the relationship between load value and drug quantity will be concave when $\beta<1$, the $\beta$ 's provided in Arkes et al. (2004) were 0.787 for cocaine and 0.802 for marijuana, implying there is very little curvature in these functions. Figures $8 \mathrm{a}$ and $8 \mathrm{~b}$ are analogous to Figures $5 \mathrm{a}$ and $5 \mathrm{c}$, but instead of showing the expected sentence exposure function, they show our calculation of the load value function as described above. As can be seen, the estimated value functions are almost linear and do not track the estimated pay functions at all.

The estimated pay functions are certainly not real data however, so the results in Figures $5 \mathrm{a}$ and $5 \mathrm{~b}$ should be taken with a grain of salt. However, as mentioned above, it is hard to come up with a story such that the relationship between load value and quantity would take on the shapes of the pay functions shown in Figures $2 \mathrm{a}$ and $2 \mathrm{~b}$. In summary, we would argue that our results suggest that it is variation load size and expected sentence exposure that are primarily correlated with pay, not load value.

\section{IV(c) - The Relationship Between Compensation and Mule Characteristics}

We can also look at whether other mule attributes are correlated with pay. Specification (1) in Table 5 again shows the results previously reported from regressing

\footnotetext{
${ }^{8}$ For example, given the formula $\mathrm{P}=\alpha \mathrm{Q}^{\beta}$, we know $\alpha=\mathrm{P} / \mathrm{Q}^{\beta}$. Therefore, if we know the price $(\mathrm{P})$ for an ounce (or $0.028 \mathrm{~kg}$ ), and the relevant $\beta$ for that drug, we can calculate $\alpha$ for each drug.
} 
reported pay on total quantity, total quantity squared, expected sentencing exposure, dummies for drug type, and a monthly linear time trend. Specification (2) shows the results after adding indicator variables for gender, citizenship, and indicator for whether citizenship was missing, dummy variables for month of arrest, and a dummy variable for the arrest happening on a weekend. As can be seen, the coefficients on the indicator variables for gender and citizenship are not statistically significant, suggesting pay is not strongly correlated with obvious attributes of the mule. Additionally, the coefficients on quantity, quantity squared, and expected sentence exposure, all remain highly statistically significant with the expected signs. The coefficients on the month of arrest and weekend arrest dummies are not shown, but none are statistically significant at the $5 \%$ level or better.

In sum, while mule compensation appears to be correlated with expected sentencing exposure and total quantity---the factors that could impact the expected sentencing risk of attempting to smuggle the load---compensation does not appear to be strongly related to other mule or load characteristics.

\section{IV(d) - Concerns about Sample Selection and Unobserved Criminal History}

The findings discussed above are, of course, based on a subsample of the total population of drug mules---namely, only the mules who got caught and were willing to say something about their compensation. Moreover, we do not account for any potential criminal history of the individuals in our analysis. Do these constraints on the data undermine the validity of our results?

As to the first constraint, we cannot absolutely rule out the possibility that the mules who get caught differ systematically in some ways from those who don't. However, we think that the possibility is unlikely. Mules who act suspiciously at the

primary screening area are probably more likely to get caught. But pre-primary dog sweeps are random, so mule competence is irrelevant in those cases. While our data does not tell us the relative distribution of pre-primary sweeps vs. booth interviews as the basis for secondary inspections, anecdotal evidence from prosecutors at the United States Attorney's office that handle these cases in the Southern District of California suggests that the former is quite common. In general however, one might argue that our sample 
over represents less experienced mules who are more likely to get caught. A related question is whether less experienced mules are paid less than more experienced mules. While interesting and important, our data does not allow us to shed any light on this.

As to whether there are systematic differences between the arrested mules who talk and the ones who remain silent - our data do show some differences. In particular, Table 6 shows how certain characteristics of the loads differ between those with valid pay data and those without. More specifically, those without pay data are divided into two categories: (i) those who confessed but did not give pay information, (ii) those who denied the charge or invoked their right to silence (and thus did not give pay data). As can be seen in Table 6, there are no statistical differences between load type, or load size conditional on type, between those with valid pay data and those who confessed but did not provide pay data. However, those who denied the charge or invoked their right to silence appear to have been more likely to be carrying harder drugs (cocaine, meth) and larger loads conditional on type of drug.

As explained above, sentencing exposure risk is much greater for hard drugs, and conditional on drug type, sentencing risk is increasing in quantity. Thus, Table 6 shows that there is an inverse relationship between sentencing risk and likelihood of confession: the riskier a mule's load is, the less likely he or she is to confess. Indeed, running a simple probit regression of an indicator variable for whether or not an individual confessed on the expected sentence exposure associated with his load suggests that being caught with a load carrying an extra year of expected sentencing exposure beyond the mean is associated with a more than three percentage point decrease in the likelihood of confessing (based on a mean of about 66 percent)---a result that is statistically significant at well beyond the $99 \%$ confidence level.

Therefore, while we think our results are representative of all of those who confess, we also think that if anything, they understate the average compensation for mules overall. Because those mules who deny the charge or invoke their right to silence are on average carrying loads with higher sentencing risk---and among the mules for whom we have valid pay data, those carrying loads with higher sentencing risk are on average paid more---we suspect that those who deny the charges or invoke their right to 
silence were paid more than those for whom we have pay data. In this way, we think our results provide a lower bound on mule compensation.

We would also argue that the negative correlation between the expected sentence exposure and confession strengthens our conclusion that mules in most cases know roughly what their cargo is and its related sentencing risk. If mules did not have this knowledge in most cases, then the observed correlation between load type and size, and willingness to talk, should not arise. ${ }^{9}$

As stated above, another issue of concern might be that we are not able to control for the criminal history of our drug mules. However, we do not feel this is a particularly strong concern. On a theoretical level, it would not seem wise for drug cartels to hire mules with significant criminal history, as such individuals would likely face heavier scrutiny at the border crossings. Moreover, even if cartels were willing to hire mules with significant criminal histories, if anything, we would suspect they would pay them less due to their potential higher likelihood of being caught.

While we do not have criminal histories for all of the individuals in our data, we are able to obtain criminal histories for a subset of our data by merging our data with the Monitoring of Federal Criminal Sentences data from 2007 and 2008 (USSC 2008, USSC 2009). The Monitoring of Federal Criminal Sentences data is compiled by the United States Sentencing Commission and contains all federal cases that were sentenced between October 2006 and September 2007 for the 2007 data, and October 2007 and September 2008 for the 2008 data. This data contains a wealth of information about each case including type of crime, criminal history, sentencing, and some demographic information.

There are, however, no unique identifiers across our data and the Monitoring of Federal Criminal Sentences data that enable a simple match. Therefore, to attempt to match the cases in our data to those in the Monitoring of Federal Criminal Sentences we

\footnotetext{
${ }^{9}$ We reject the other possible explanation, which is that agents systematically tell mules what the cargo type and size was, before reading them their rights and getting the invocation/confession/denial response. We can say as a matter of personal experience with these interviews that that is not the standard practice of ICE agents in California; more importantly, as a legal matter, such a practice would likely violate Miranda and render any subsequent confession inadmissible (because telling the mule the nature of the cargo would constitute "interrogation" under Rhode Island v. Innis, and per Miranda, custodial interrogation must be preceded by a valid waiver). We're not saying it has never happened; rather, it is not policy, it does not happen systematically, and if it did occur, it would undermine the prosecution's case.
} 
first restricted the Monitoring of Federal Criminal Sentences data to only drug trafficking and drug possession cases, then matched on sentencing year, sentencing month, type of drug, amount of drug, and sentence length. Using this procedure we matched just over $38 \%$ of the 2007 and 2008 cases in our data (subsequently referred to as "matched cases"). The reason for this somewhat low match rate is likely the relatively common practice of "discounting," or lowering the charged drug amounts during the plea negotiation phase prior to sentencing, especially for those defendants with a minimal criminal history. Hence, the load sizes we observe in our data, taken directly at the time the drugs were found, will often be greater than the load sizes used for sentencing, especially for those with minimal criminal histories. This suggests that, if anything, our matched cases will over-represent defendants with more substantial criminal histories.

Consistent with our findings regarding sentence length, we find just over $78 \%$ of these matched cases indeed were deemed eligible for the safety valve (an outcome reported in the Monitoring of Federal Criminal Sentences data). As argued above, such sentencing is only available in circumstances where no guns were used or violence was committed, the defendant was determined to be fully cooperative, and the defendant had was determined to have a criminal history of Category I (i.e., a minimal criminal history). We indeed find that $82 \%$ of our matched defendants were determined to have a Category I criminal history, the lowest possible level, indicating a minimal criminal history. As stated above, we think that, if anything, our matched cases overstate the extent of more serious criminal histories of the defendants in our overall data. A complete breakdown of the criminal history categories for individuals in our matched data is shown in Table 7.

In addition to the fact that only a small minority of the defendants in our data appear to have substantial criminal histories, those that do have substantial criminal histories do not appear to be paid differently. For example, mean pay for those determined to have a Category I criminal history is $\$ 1,575$, while the mean pay for those defendants determined to have a criminal history category greater than I is $\$ 1,572$ (median pay is $\$ 1,352$ and $\$ 1,170$ respectively). Moreover, if anything, drug mules with criminal histories appear to be carrying slightly less valuable loads according to the Caulkins and Padman (1993) and Caulkins et al. (2009) models. For example, the mean load value of loads for those defendants determined to have the minimal Category I 
criminal history is $\$ 54,267$, compared to a mean load value of $\$ 42,646$ for those defendants with greater than Category 1 criminal history (median load values $\$ 34,179$ and $\$ 28,289$ respectively).

\section{V - Summary and Conclusions}

This paper uses a novel dataset to explore the underground economy of smuggling drugs into the U.S. via ports of entry along the California-Mexico border. Our findings show that the drug loads these mules carry are on average large and quite valuable on the street, often on the order of tens of thousands dollars or more wholesale. Moreover, we find that mules are arguably quite well paid for their courier work, generally being paid between one and two thousand dollars for a day's work---a daily wage far in excess of the average wage rates on either side of the border.

This is somewhat in contrast to Levitt and Venkatesh's (2000) study of the finances of a Chicago street gang, who found that low level drug dealers earned wages not much in excess of minimum wage. We suspect that one reason why the drug couriers are paid substantially more than the low level drug dealers is that these labor markets are fundamentally different. While Levitt and Venkatesh (2000) argue that low level drug dealers are essentially competing in a labor market tournament, where some "winners" will eventually make it up the ranks eventually obtaining much higher earnings, many of the narratives of individuals in our data suggest that drug mules are essentially outside of the drug retail operation and not looking to "work their way up" within the organization. ${ }^{10}$

We also find that the characteristics of the mule (gender and citizenship) generally do not have significant impacts on mule compensation. However, we do find evidence that this illegal and unregulated labor market behaves in a manner consistent with basic economic theory of competitive markets. Namely, compensating wage differentials appear to arise for otherwise similar work that involves higher risk---in this case longer expected incarceration associated with being caught with the load carried. In particular, cocaine and methamphetamine mules are paid on average over $\$ 1,200$ more for an

\footnotetext{
${ }^{10}$ The post-arrest interviews from which we draw our data often include details about the background and recruitment of the arrestee.
} 
additional year of sentencing risk if caught. We also find that for marijuana, where sentences are quite short and exhibit little variation with load size but load sizes can be very large and exhibit a lot of variation, larger loads are associated with higher compensation. Again, this finding is consistent with a compensating differential for higher expected sentencing risk if, as is likely, larger loads are more likely to be detected.

The extent to which $\$ 1,200$ for an additional year of sentencing risk if caught is a large or small wage premium is a matter of opinion. One admittedly tenuous way to interpret this finding is to consider what it might imply about how mules value the utility cost of a year in prison. Specifically, if we consider risk-neutral drug mules (admittedly a strong assumption), and suppose the likelihood of detection at the border is roughly $7.5 \%$ (consistent with our argument in Appendix II), this would imply that mules would need to be compensated about $\$ 16,000$ for spending an additional year in jail with certainty (i.e., \$1,200/0.075), which is roughly in line with the average annual income for Mexican residents residing near the U.S. border (Anderson and Gerber 2008). This finding is consistent with Reuter's (1990) speculation that compensation for incarceration risk is driven largely by opportunity cost of lost wages. It is also near the lower bound on the value of one life year for Mexican prostitutes as estimated by Gertler, Shah, and Bertozzi (2005). As another point of comparison, using a bail experiment conducted in the early 1980's in Philadelphia, Abrams and Rohlfs (2011) estimate that the typical defendant in their data would be willing to pay roughly $\$ 1,500$ (in 2010 dollars) for 90 days of freedom, or crudely $\$ 6,000$ for a year of freedom. Particularly for these populations however, willingness to pay to avoid incarceration may differ substantially from what they are willing to accept to be incarcerated.

In general, our findings reveal that in an unregulated and illegal market such as the one for drug mules, basic predictions of competitive labor markets seem to hold---on average, mules appear to be generally knowledgeable about what they are carrying and competitive forces lead to a compensating wage premium being paid to those carrying higher risk loads. This suggests that efforts to increase drug detection at border crossings can affect the revenue stream going to drug cartels not only through lessening their ability to get drugs into the U.S., but also by increasing their labor cost for couriers. 
Finally, one might be concerned that our results are limited in their scope, as we only have data on drug mules caught at official border crossings on the CaliforniaMexico border. While we acknowledge that different labor markets and labor market rules may be happening in other areas, and indeed we hope to look this very issue in future work, we do not feel this makes our findings here less important. Analogous to the previously cited work by Levitt and Venkatesh (2000) on the economics of one drug gang on the south side of Chicago, and Gertler, Shah, and Bertozzi's (2005) study of sex workers in Mexico, and Gathmann's (2008) study of migrant smuggling along the U.S.Mexico border, progress in understanding black markets generally starts by analyzing particular markets where data can be obtained. 


\section{Appendix I - Notes on Likelihood of Detection}

The Office of National Drug Control Policy (ONDCP) estimates that in 2007 (the most recent year for which data is published) cocaine shipments from South America (where almost all of the world's coca crops are cultivated) to the United States totaled between 545 and 707 metric tons, with a best estimate of 626 metric tons that "departed from South America toward the United States" (ONDCP 2007). The ONDCP estimates that $90 \%$ of the cocaine coming to the U.S. comes through the Mexican corridor, either up the Pacific coast of Mexico or the Caribbean coast of Mexico, with the other $10 \%$ going through the Caribbean Islands to Miami. Both of the major routes through Mexico include crossing points on the Southwest border: the Pacific route terminates in Tijuana and Mexicali and crosses through the California ports of entry, and the Caribbean route terminates in Juarez and Tamaulipas and crosses through the Texas ports of entry. Thus we would estimate 563 tons $(626 * 0.9)$ of the cocaine headed to the U.S. will come via routes headed toward the Southwest border.

However, in 2007, 209 metric tons were seized in all transit zones before reaching the U.S. border, so we estimate that 188 tons $(209 * 0.9)$ of the cocaine en route to the Southwest border was seized before reaching the border. Therefore, our best estimate of the amount of cocaine arriving at the Southwest border region in 2007 is roughly 375 tons $(563$ - 188). Finally, in 2007, another 27 tons of cocaine was seized at all "arrival zone" areas (areas including both the border crossing areas and areas just before the U.S. border, including both areas near the border and in the oceans off the coasts).

If we again assume that $90 \%$ of these arrival zone seizures took place in the Southwest Border region, this means a total of 24.3 tons were seized at the "arrival zone" areas at or near the southwestern United States borders. Since only 11 tons of cocaine were actually seized at the southwest border crossings in 2007 (NDIC 2008), roughly 13.3 tons of the arrival zone seizures must have taken place prior to crossing the border. Therefore, our best estimate is that about 362 tons of cocaine $(375-13.3)$ made it as far 
as the border itself. Of that 362 tons, 11 tons were seized at the border, meaning only about $3 \%$ of the cocaine that made it to the U.S. -Mexico border was intercepted. ${ }^{11}$

Caveats, of course, abound: the seizure data does not specify type of importation modality, and includes all seizures made within 150 miles of the border. So the amount actually seized in port-of-entry vehicle smuggling will be somewhat less than the total reported seizure amount. This would mean that the detection rate for port-of-entry vehicle loads will be lower than the figure calculated above. Moreover, the use of other importation modalities (e.g. tunnels, boats, and planes) lowers the total amount imported via port-of-entry vehicle smuggling, which would mean that the detection rate for portof-entry vehicle loads would be higher.

Nonetheless, the production-based and consumption-based estimates are close enough that we feel reasonably confident in asserting that the likelihood of detection for drug smugglers coming through ports of entry is certainly less than one in ten and probably closer to one in twenty or less.

Similar estimates for the other drugs are somewhat more speculative because their sources are more diffuse, so that we lack a reliable "total volume headed to the U.S." estimate. However, Kilmer et al. (2010) attempted to estimate the share of U.S.consumed marijuana that is imported from Mexico. They estimate that Mexican-grown marijuana accounts for between 40 and $67 \%$ of annual U.S. consumption, which they estimate at approximately 3,300,000 kilos. At the observed mean marijuana load size of around 80 kilos, that would be around 42,000 marijuana trips a year. We know, though, that vehicle smuggling is not the only modality for marijuana smuggling. Tunnels and backpack loads (and ultralights and pangas) are also common importation modalities, and we simply lack data on the relative distribution of the various methods. The 2011 National Drug Threat Assessment states that backpack loads brought across the desert in Arizona may be the primary marijuana importation modality. While we simply cannot definitively say how much marijuana comes in through official border crossings relative to these other methods, for purely illustrative purposes let us use a relatively conservative

${ }^{11}$ Using a consumption based measure, Kilmer et al (2010) estimate 252 metric tons of importquality cocaine make it into the United States. Taking this estimate and including the 11 tons seized at the border, then about $4 \%$ of the cocaine coming through the U.S.-Mexico border was intercepted. 
estimate that one-quarter of total Mexican marijuana importation was done by vehicles through California ports of entry. That would be some 10,000 smuggling trips in a given year. There are around 500 federal marijuana smuggling cases brought each year arising from California POEs, and again using a conservative estimate that another 500 cases that result in state charges or apprehensions followed by declinations (for small Imperial County loads, for example). These conservative calculations would still only then translate to a roughly $10 \%$ detection rate, which is higher than the predicted cocaine detection rate calculated above, but still arguably quite low.

Kilmer et al. (2010) have also attempted consumption estimates for heroin and meth. They estimate total consumption of 101 metric tons of heroin (of import-level purity), of which they estimate roughly $60 \%$ is imported from Mexico. That would mean 60.6 tons imported through the Southwest border. Given the 2011 National Drug Threat Assessment reports that 0.905 metric tons were seized on and around the border in 2010, which would imply a detection rate of around $1.5 \%$.

We are unable to perform a similar calculation for meth, however, because meth is produced in the U.S. as well as in Mexico, and the NDTA includes in its "border area" seizures report all drugs seized within 150 miles of the border-namely, all of Southern California, and much of Arizona, New Mexico, and Texas. The NDTA figure thus includes all domestic meth-lab seizures as well as border seizures. Better data may help us to refine our estimate.

In general, we doubt the seizure rates are higher for meth and heroin than for cocaine because meth and heroin loads are generally smaller than cocaine loads. Further, a significant portion of border seizures are random "pre-primary" sweeps, in which the drug dog is simply walked through the line of cars awaiting inspection. We do think it likely that detection rates for marijuana are significantly higher than for the other drugs, given the much larger load sizes and stronger smell. Conservatively, though, we feel safe in saying that detection rates are less than less than $10 \%$ for all drug mules crossing U.S.Mexico ports-of-entry, and likely more on the order of $5 \%$ or less. 


\section{Appendix II - Notes on State versus Federal Prosecutions}

In the Southern District of California, all hard-narcotics importation cases (that is, coke, meth, and heroin) are taken by federal prosecutors, so our dataset contains the full universe of cocaine, meth, and heroin border busts in California. In addition, our data contains the full universe of marijuana border busts for the ports in Imperial County (Andrade and the two Calexico ports) because the Imperial County District Attorney does not accept border-bust cases. However, our dataset is missing some marijuana borderbusts from San Diego County ports (San Ysidro, Otay, and Tecate), because the San Diego County District Attorney prosecutes some marijuana border busts.

Without obtaining similar data from the San Diego District Attorney's office (unavailable at the time of this manuscript), we have no direct evidence as to whether the mules prosecuted in state court for San Diego County busts differ systematically from those busted in Imperial County or the other states. If state sentencing for marijuana importation differed dramatically from federal sentencing, then we might expect to see some differences. But it does not differ dramatically. The San Diego DA's standard offer is one day of incarceration per pound. Our data shows us how the day-a-pound regime compares to observed federal sentencing. For example, 930 of our California marijuana mules got federal sentences of less than 6 months, which is around $40 \%$ of the federal marijuana cases in the district. The mean sentence for that group, excluding four tractor-trailer acquittals, with load sizes in the thousands of kilos, was 4.61 months (140 days), and the mean load size was 34.7 kilos (76.5 pounds). The top quintile (by sentence) of that set had a mean sentence of 5.05 months (154 days) and a mean load size of 35.4 kilos (78.04 pounds). For them, in other words, federal sentences are longer by around 76 days than a day-a-pound sentence would be. By comparison, for the bottom quintile of cases in which the defendant received a prison sentence, the mean sentence was 1.37 months (42 days), and the mean load size was 18.64 kilos (41.1 pounds) which is almost exactly a day a pound. And another 200 cases got probation - though in most of those, the defendant remained in jail between arrest and sentencing. 


\section{Bibliography}

Abrams, David and Chris Rohlfs. (2011). Optimal Bail and the Value of Freedom:

Evidence from the Philadelphia Bail Experiment." Economic Inquiry 49: 750-770.

Anderson, Joan and James Gerber. (2008). Fifty Years of Change on the U.S.-Mexico Border: Growth, Development, and Quality of Life. Austin TX: University of Texas Press.

Arkes, Jeremy, Rosalie Liccardo Pacula, Susan Paddock, Jonathan Caulkins, and Peter Reuter. (2004). Technical Report for the Price and Purity of Illicit Drugs through 2003.

Campbell, Howard (2009), Drug War Zone: Frontline Dispatches from the Streets of El Paso and Juarez. Austin TX: University of Texas Press.

Caulkins, Jonathan, Honora Burnett, and Edward Leslie. (2009). "How Illegal Drugs Enter and Island Country: Insights from Interviews with Incarcerated Smugglers." Global Crime 10(1): 66-93.

Caulkins, Jonathan and Robert MacCoun. (2003). "Limited Rationality and the Limits of Supply Reduction." Journal of Drug Issues 33(2): 433-464.

Caulkins, Jonathan and Rema Padman. (1993). "Quantity Discounts and Quality Premia for Illicit Drugs." Journal of the American Statistical Association 88(423).

Caulkins, Jonathan and Peter Reuter. (2006). "Illicit Drug Markets and Economic Irregularities.” Socio-Economic Planning Sciences 40: 1-14.

Costa Storti, Claudia and Paul De Grauwe. (2008). "Illicit Trade and Globalization: Modeling the Cocaine and Heroin Markets in the Era of Globalization and Drug Reduction Policies." Venice International University, Center for Economic Studies, (2008).

Decker, Scott H., and Margaret Townshend Chapman. (2008), Drug Smugglers on Drug Smuggling: Lessons from the Inside. Philadelphia PA: Temple University Press.

Gathmann, Christina. (2008). "Effects of Enforcement on Illegal Markets: Evidence from Migrant Smuggling Along the Southwestern Border." Journal of Public Economics 92: 1926-1941.

Gertler, Paul, Manisha Shah, and Stefano M. Bartozzi. (2005). "Risky Business: The Market for Unprotected Commercial Sex." Journal of Political Economy 113(3): 518550 .

Kilmer, Beau, and Jonathan Caulkins, Brittany Bond, and Peter Reuter (2010), "Reducing Drug Trafficking Revenues and Violence in Mexico." RAND Occasional Paper Series OP-325-RC. 
Levitt, Steven D. and Sudhir A. Venkatesh. (2000). "An Economic Analysis of a DrugSelling Gang's Finances." Quarterly Journal of Economics 115(3):755-89.

MacCoun, Robert and Peter Reuter. (1992). "Are the Wages of Sin $\$ 30$ and Hour? Economic Aspects of Street-Level Drug Dealing." Crime and Delinquency 38(4): 477492.

National Drug Intelligence Center (NDIC). (2008). National Drug Threat Assessment 2009. December 2008.

National Drug Intelligence Center (NDIC). (2011). National Drug Threat Assessment 2011. August 2011.

Neal, Derek and William Johnson. (1996). "The Role of Premarket Factors in BlackWhite Wage Differences." The Journal of Political Economy 104(5): 869-895.

Office of National Drug Control Policy (ONDCP). (2008). Cocaine Smuggling in 2007.

O'Neill, June and Solomon Polachek. (1993). "Why the Gender Gap in Wages Narrowed in the 1980s." Journal of Labor Economics 11(1): 205-228.

Rivest, Louis-Paul. (1994). "Statistical Properties of Winsorized Means for Skewed Distributions." Biometrica 81(2): 373-383.

Reuter, Peter. (1990). Money from Crime: A Study of the Economics of Drug Dealing in Washington, D.C. Rand Corporation.

Reuter, Peter and Mark Kleiman. (1986). "Risks and Prices: An Economic Analysis of Drug Enforcement" Crime and Justice: An Annual Review 7: 289-340.

Rosen, Sherwin. (1986). "The Theory of Equalizing Differences." In Orley C. Ashenfelter \& Richard Layard, eds., Handbook of Labor Economics, Vol 1, Amterdam: Elsevier: 641-692.

United States Department of Justice. (2008). National Illicit Drug Prices (June 2008). www.usdoj.gov/ndic.

United States Sentencing Commission. (2008). Monitoring of Federal Criminal Sentences, 2007. ICPSR22623-v2. Ann Arbor, MI: Inter-university Consortium for Political and Social Research [distributor].

United States Sentencing Commission. (2009). Monitoring of Federal Criminal Sentences, 2008. ICPSR25424-v2. Ann Arbor, MI: Inter-university Consortium for Political and Social Research [distributor]. 
Table 1 - Load Size by Drug

\begin{tabular}{rccc}
\hline & Cocaine & Meth & Marijuana \\
\hline Load Size $(\mathrm{kg})$ & & & \\
Mean & 22 & 9 & 85 \\
Median & 22 & 8 & 42 \\
90th \%ile & 36 & 19 & 102 \\
10th \%ile & 6 & 1 & 18 \\
& & & \\
\hline
\end{tabular}

Fig 1: Quantity Distribution - by Drug
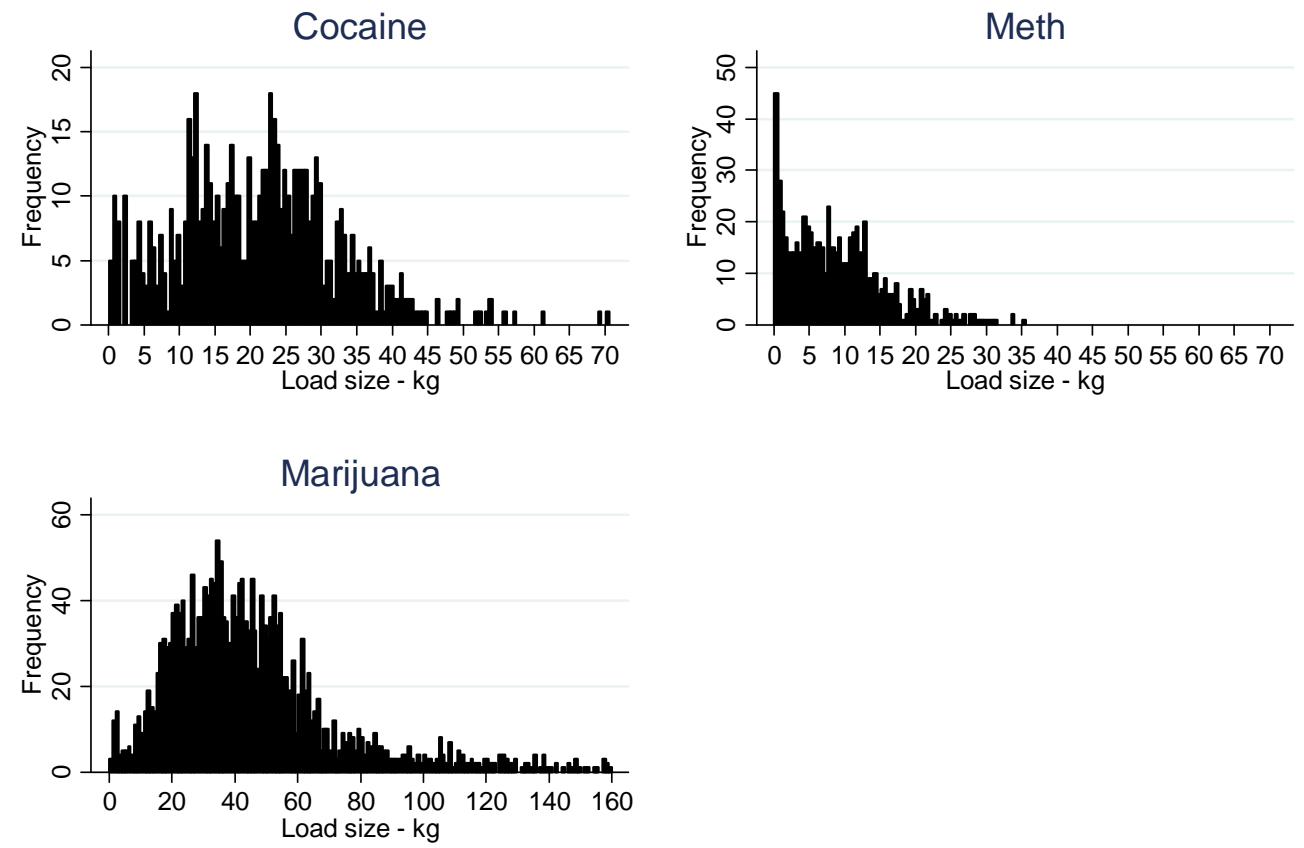
Table 2 - Average Pay by Drug

\begin{tabular}{lcccc}
\hline & All Drugs & Cocaine & Meth & Marijuana \\
\hline Whole Sample & \multicolumn{4}{c}{} \\
mean & $\$ 1,643$ & $\$ 2,272$ & $\$ 1,719$ & $\$ 1,464$ \\
median & $\$ 1,313$ & $\$ 2,020$ & $\$ 1,500$ & $\$ 1,070$ \\
10 th \% & $\$ 505$ & $\$ 520$ & $\$ 404$ & $\$ 505$ \\
90 th \% & $\$ 3,030$ & $\$ 4,000$ & $\$ 3,432$ & $\$ 2,525$ \\
\hline obs & 1888 & 325 & 298 & 1265 \\
\hline Trimmed and Winsorized Sample & & \\
\hline mean & $\$ 1,604$ & $\$ 2,207$ & $\$ 1,834$ & $\$ 1,395$ \\
median & $\$ 1,313$ & $\$ 2,020$ & $\$ 1,515$ & $\$ 1,060$ \\
10 th \% & $\$ 505$ & $\$ 700$ & $\$ 500$ & $\$ 510$ \\
90 th \% & $\$ 3,030$ & $\$ 3,535$ & $\$ 3,500$ & $\$ 2,525$ \\
\hline obs & 1369 & 243 & 204 & 922 \\
\hline \multicolumn{5}{c}{} \\
\hline
\end{tabular}


Table 3: Mandatory Minimums, Sentencing Guidelines, and Actual Sentences

\begin{tabular}{|c|c|c|c|c|}
\hline & $\begin{array}{c}\text { Base Mandatory } \\
\text { Minimum (months) }\end{array}$ & $\begin{array}{l}\text { Base Guideline } \\
\text { Range (months) }\end{array}$ & $\begin{array}{r}\text { Actual Avg. Sentence } \\
\text { Length (months)* }\end{array}$ & Obs.* \\
\hline Marijuana & & & & 0 \\
\hline $0.25-1 \mathrm{~kg}$ & n.a. & $0-6$ & - & 0 \\
\hline $1-2.5 \mathrm{~kg}$ & n.a. & $6-12$ & 7 & 21 \\
\hline $2.5-5 \mathrm{~kg}$ & n.a. & $10-16$ & 11 & 3 \\
\hline $5-10 \mathrm{~kg}$ & n.a. & $15-21$ & 5 & 28 \\
\hline $10-20 \mathrm{~kg}$ & n.a. & $21-27$ & 6 & 167 \\
\hline $20-40 \mathrm{~kg}$ & n.a. & $27-33$ & 8 & 615 \\
\hline $40-60 \mathrm{~kg}$ & n.a. & $33-41$ & 10 & 505 \\
\hline $60-80 \mathrm{~kg}$ & n.a. & $41-51$ & 15 & 167 \\
\hline 80 - 100kg & n.a. & $51-63$ & 21 & 68 \\
\hline $100-400 \mathrm{~kg}$ & 60 & $63-78$ & 22 & 23 \\
\hline $400-700 \mathrm{~kg}$ & 60 & $78-97$ & - & 0 \\
\hline 700 - 1,000kg & 60 & $97-121$ & - & 0 \\
\hline \multicolumn{5}{|l|}{ Meth } \\
\hline $0.20-0.35 \mathrm{~kg}$ & 60 & $78-97$ & 45 & 2 \\
\hline $0.35-0.50 \mathrm{~kg}$ & 60 & $97-121$ & 56 & 11 \\
\hline $0.50-1.5 \mathrm{~kg}$ & 120 & $121-151$ & 41 & 46 \\
\hline $1.5-5 \mathrm{~kg}$ & 120 & $151-188$ & 55 & 88 \\
\hline $5-15 \mathrm{~kg}$ & 120 & $188-235$ & 60 & 231 \\
\hline$>=15 \mathrm{~kg}$ & 120 & $235-293$ & 59 & 51 \\
\hline \multicolumn{5}{|l|}{ Cocaine } \\
\hline $0.2-0.3 \mathrm{~kg}$ & n.a. & $33-41$ & - & 0 \\
\hline $0.3-0.4 \mathrm{~kg}$ & n.a. & $41-51$ & 12 & 1 \\
\hline $0.4-0.5 \mathrm{~kg}$ & n.a. & $51-63$ & - & 0 \\
\hline $0.5-2 \mathrm{~kg}$ & 60 & $63-78$ & 19 & 14 \\
\hline $2-3.5 \mathrm{~kg}$ & 60 & $78-97$ & 32 & 11 \\
\hline $3.5-5 \mathrm{~kg}$ & 60 & $97-121$ & 51 & 14 \\
\hline $5-15 \mathrm{~kg}$ & 120 & $121-151$ & 41 & 130 \\
\hline $15-50 \mathrm{~kg}$ & 120 & $151-188$ & 47 & 327 \\
\hline 50 - 150kg & 120 & $188-235$ & - & 0 \\
\hline$>=150 \mathrm{~kg}$ & 120 & $235-293$ & - & 0 \\
\hline
\end{tabular}

*For "Trimmed" Sample. Sentencing Guidelines for quantities less than $0.25 \mathrm{~kg}$ are not shown since we exclude them from our data. "Base" refers to mandatory minimums and guidelines for defendants with minimal criminal history and no exacerbating factors like bodily injury or gun possession. 
Figure 2a: Expected Sentence Exposure and Pay - Cocaine (Zero Order Polynomial Local Smoothing)

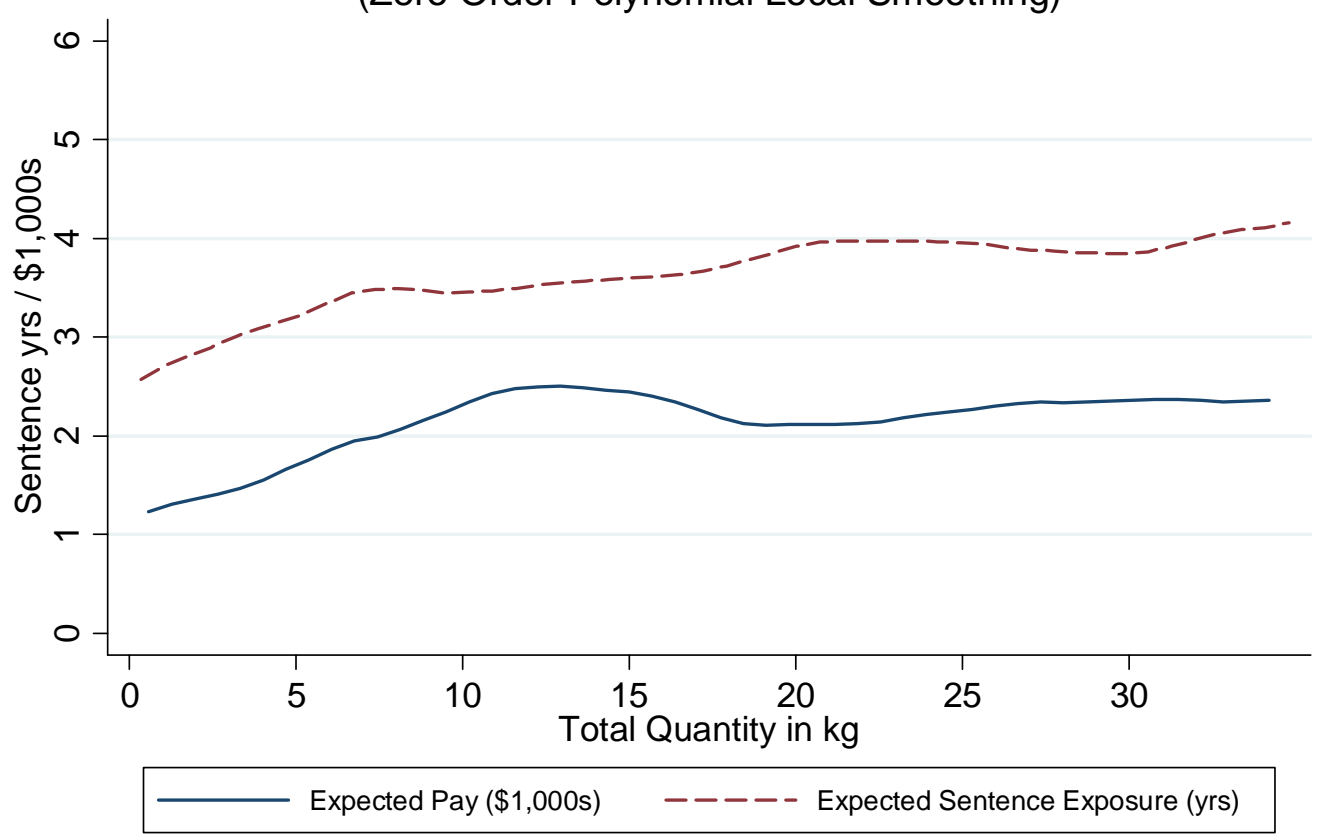

Figure 2b: Expected Sentence Exposure and Pay - Meth (Zero Order Polynomial Local Smoothing)

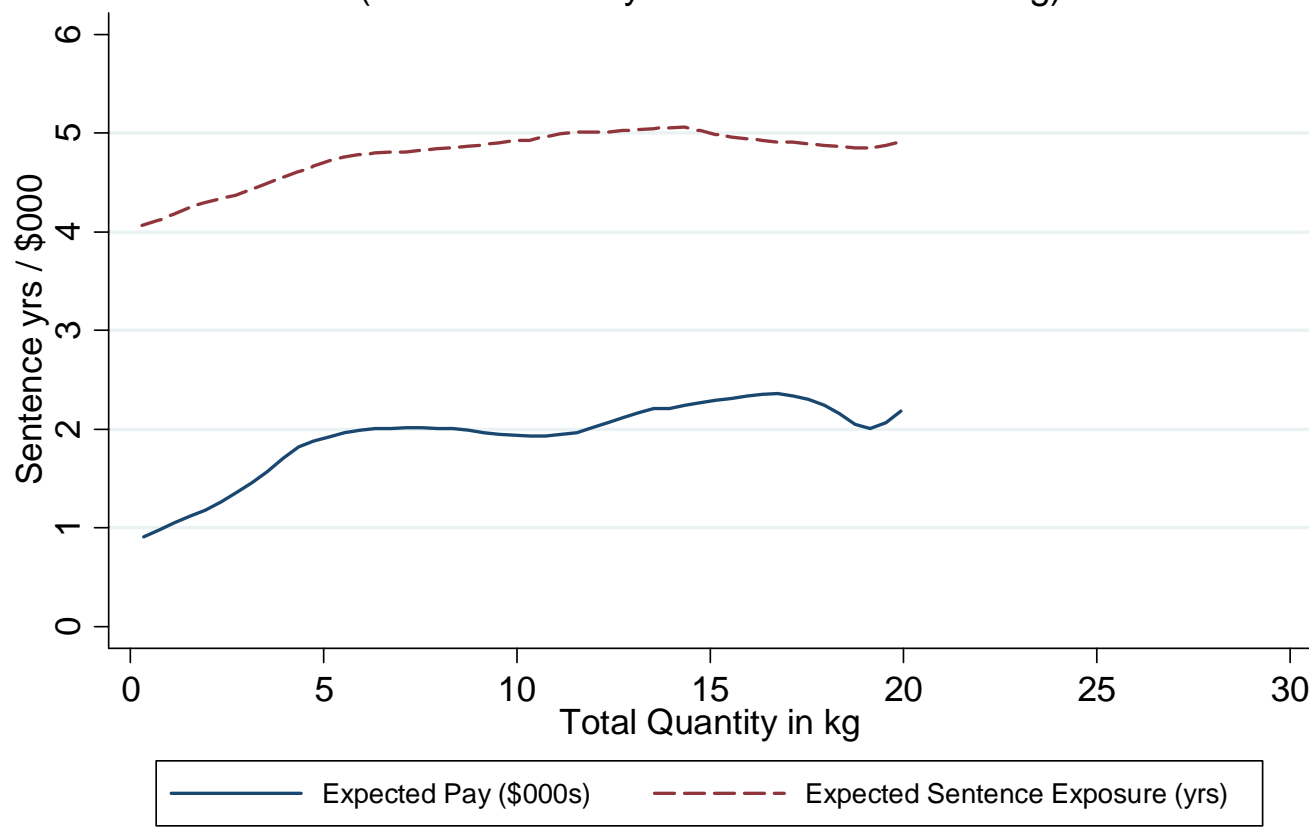


Figure 2c: Expected Sentence Exposure and Pay - Marijuana (Zero Order Polynomial Local Smoothing)

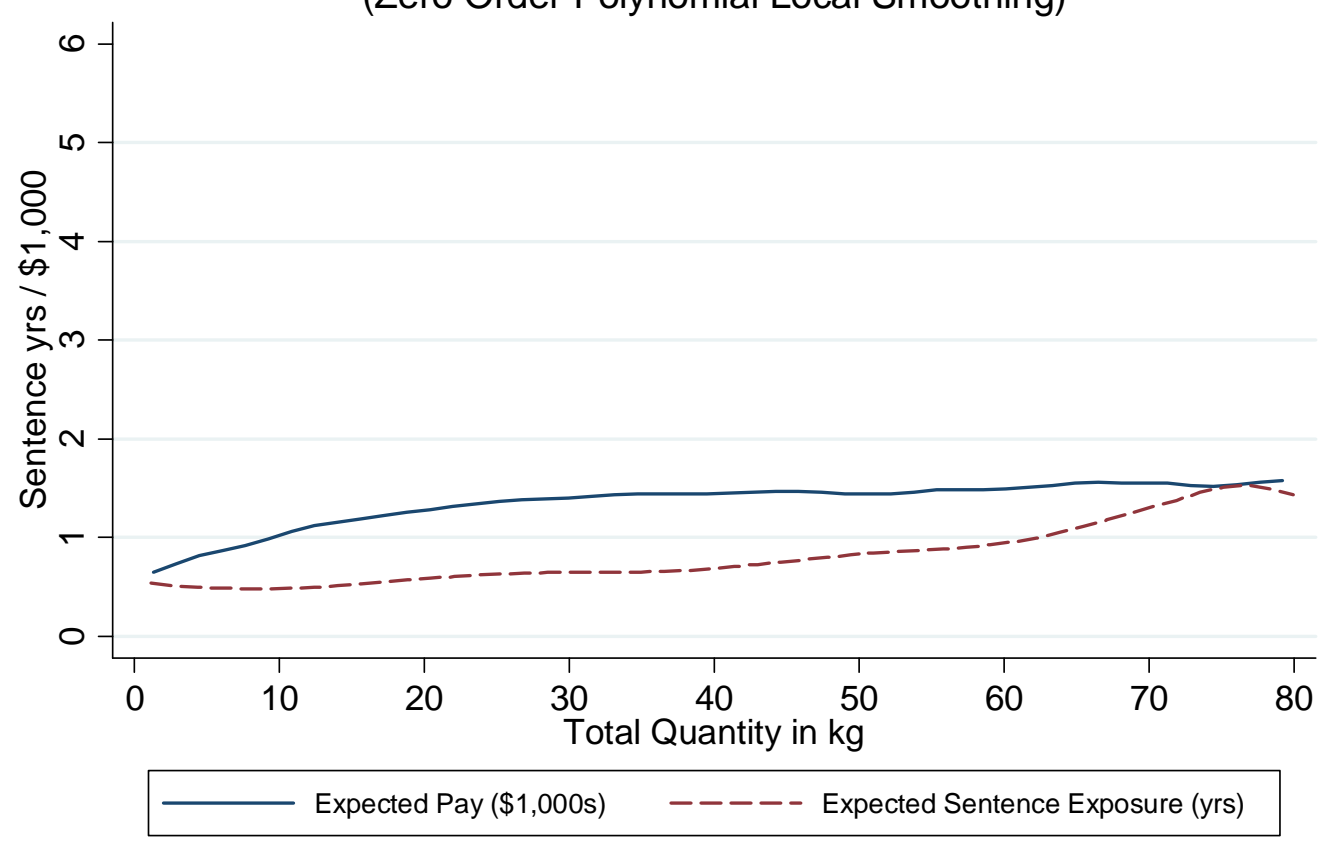


Figure 3a: Expected Sentence Exposure and Pay - Cocaine (First Order Polynomial Local Smoothing)

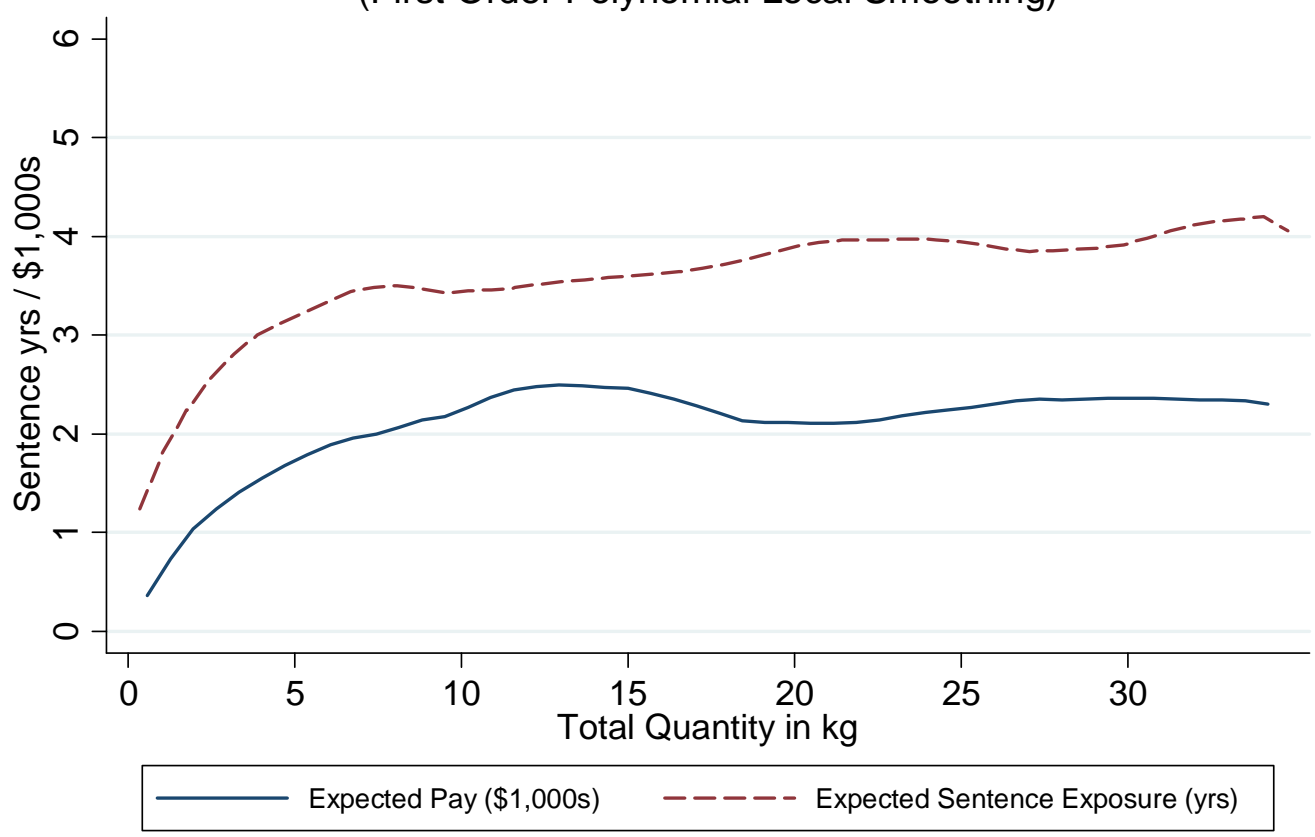

Figure 3b: Expected Sentence Exposure and Pay - Meth (First Order Polynomial Local Smoothing)

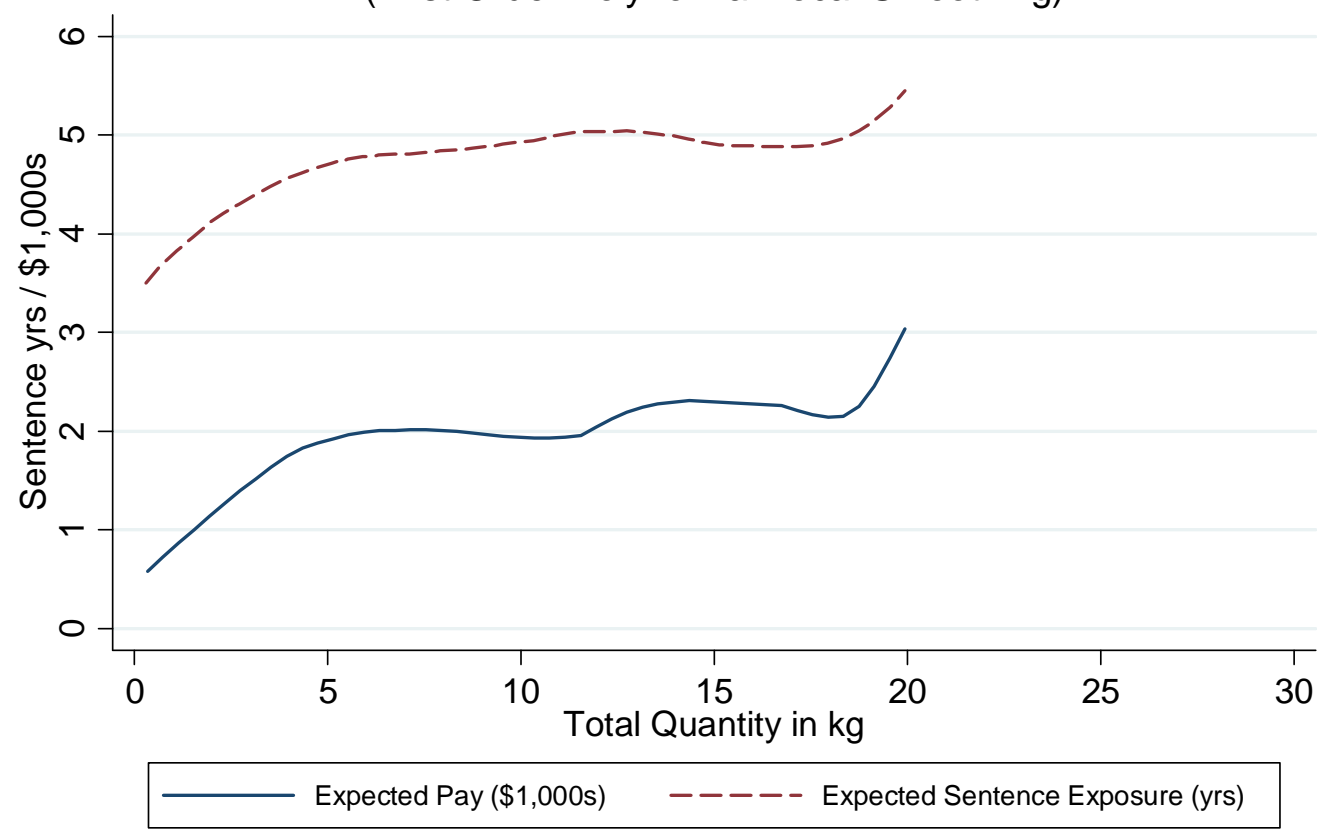


Figure 3c: Expected Sentence Exposure and Pay - Marijuana (First Order Polynomial Local Smoothing)

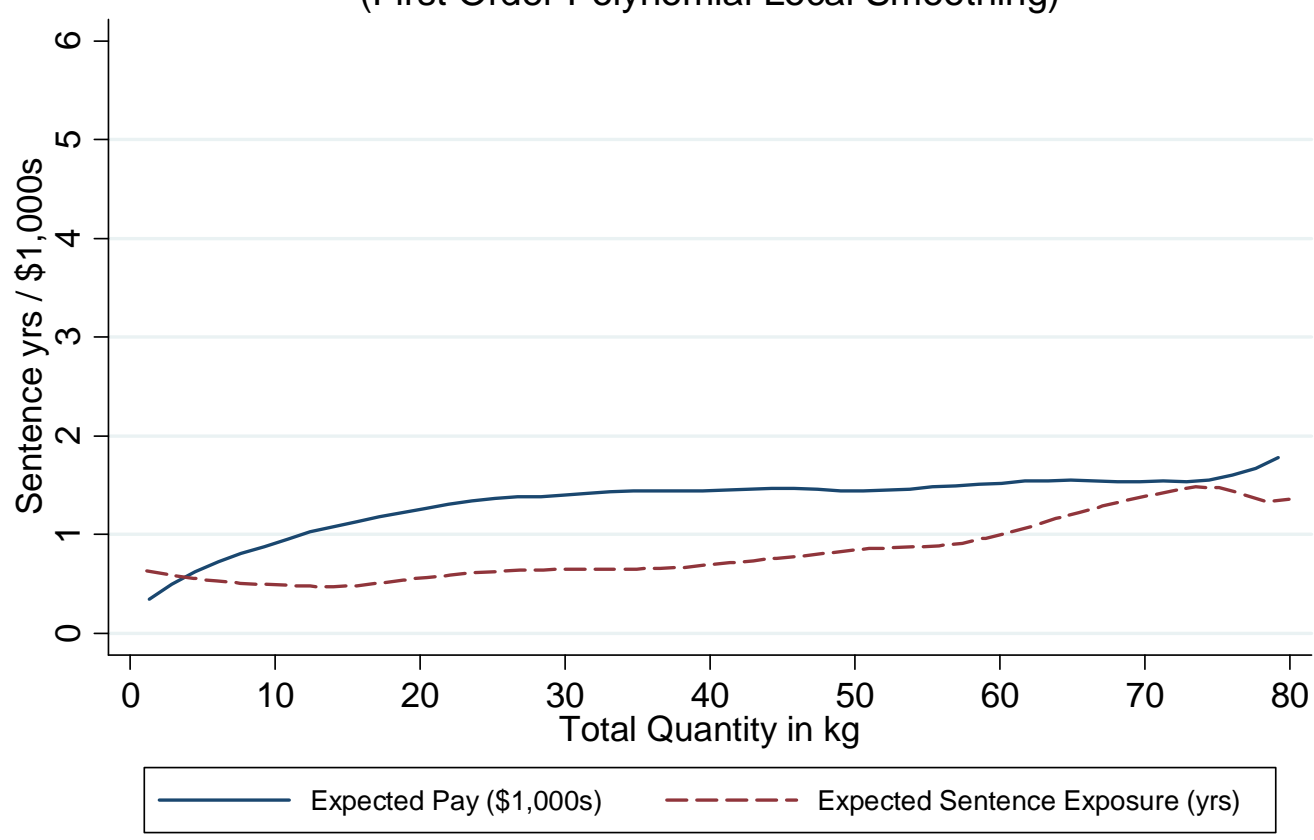



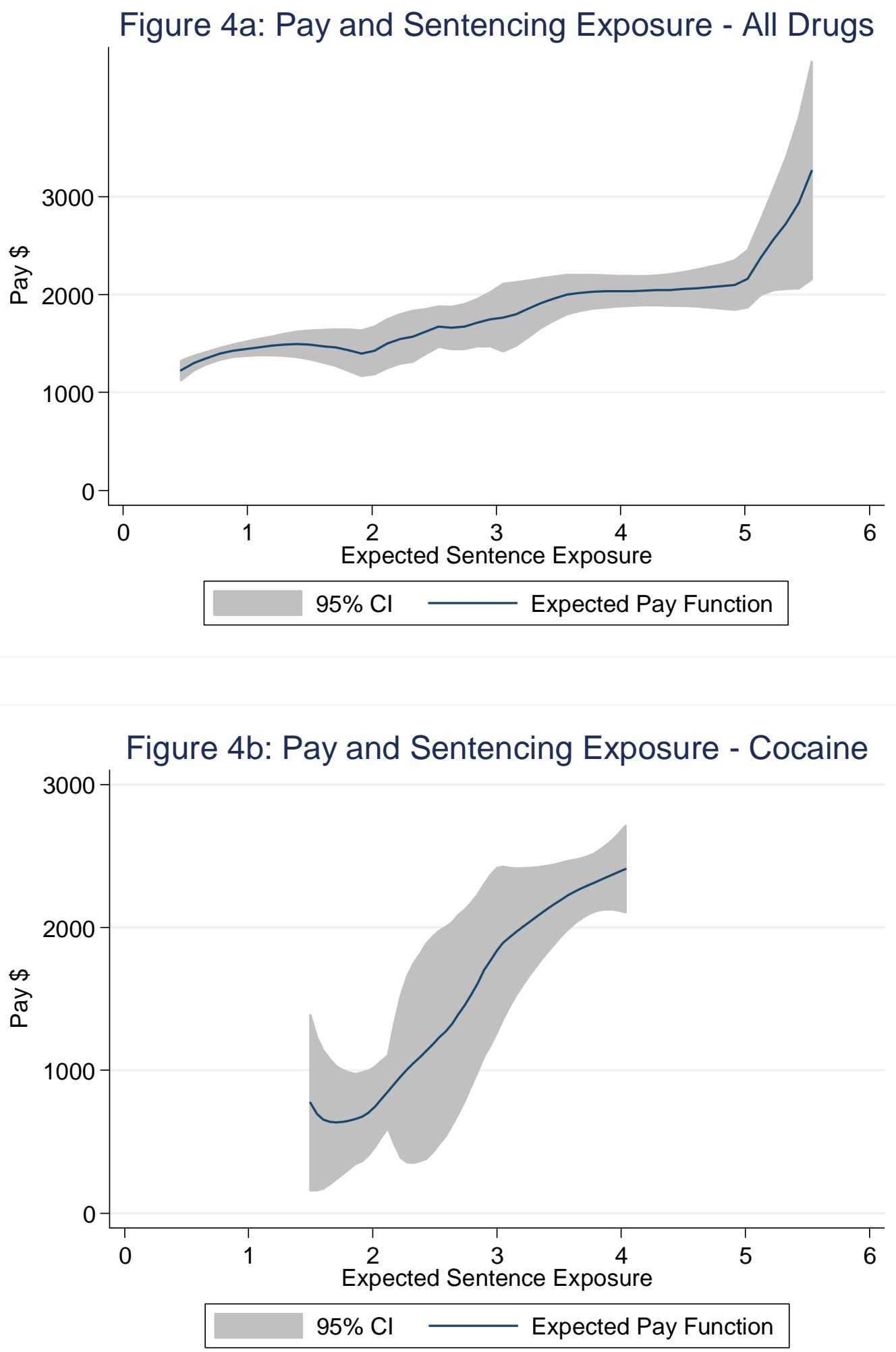

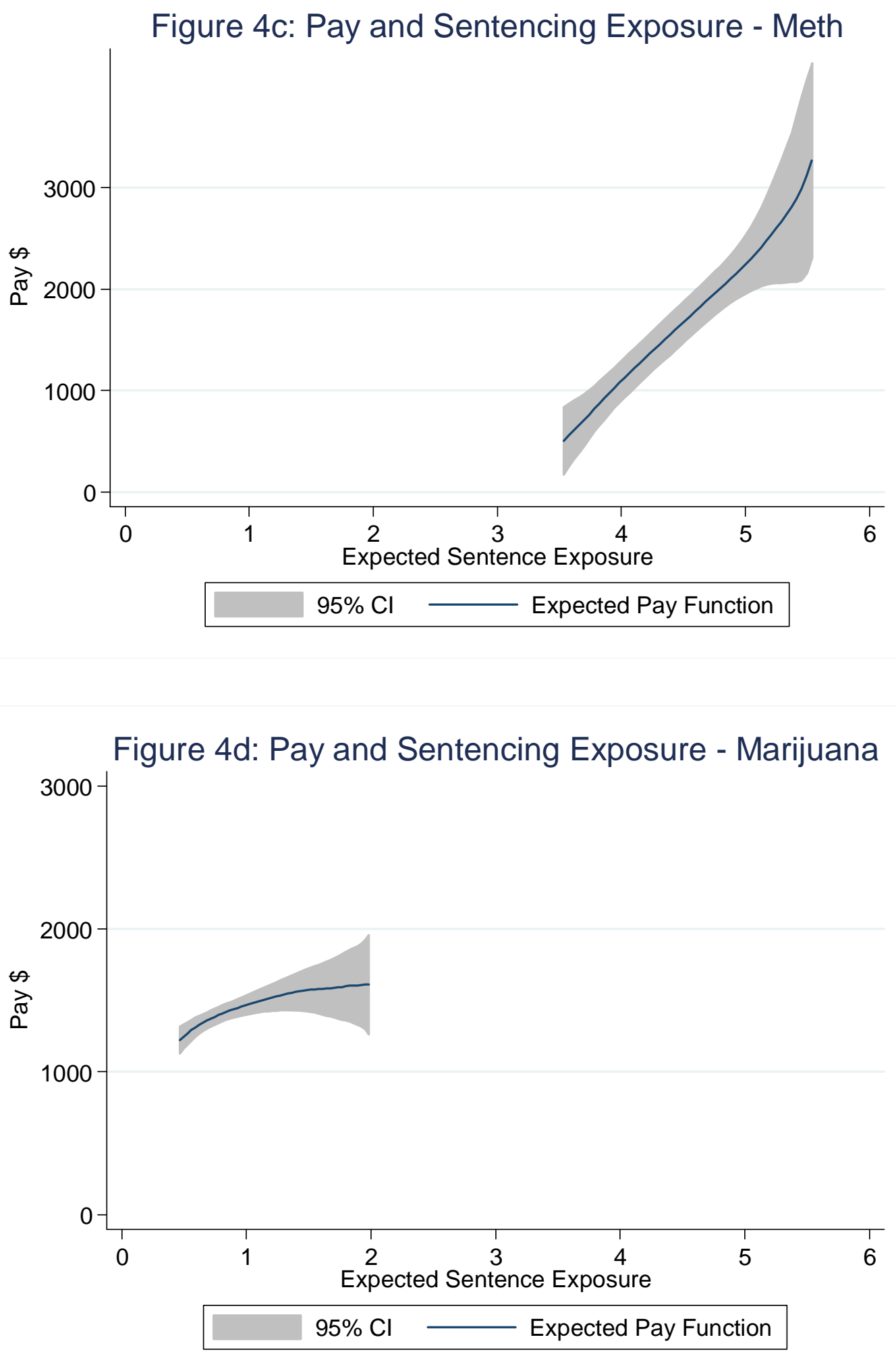
Table 4a: OLS Regressions - Pay vs Expected Sentence Exposure

\section{(1) - All Drugs (2) - Cocaine (3) - Meth (4) - Marj}

Total Quantity

$17.77^{* * *}$

(5.320)

$-63.39$

$-192.3$

$20.10 * * *$

Total Quantity Squared

$-0.229 * * *$

$(99.44)$

(184.9)

(4.690)

(0.0527)

1.275

9.085

$-0.177^{* *}$

Expected Sentence Exposure

$728.3^{* * *}$

(2.045)

(7.900)

(0.0729)

(114.2)

$1,205^{* *}$

248.4

$-967.4^{* * *}$

Meth Load

(592.0)

1,401**

(418.0)

(178.3)

Marijuana Load

$1,302^{* * *}$

(373.3)

Time

$8.334 * * *$

11.92*

$-0.539$

$9.230 * * *$

(2.244)

(6.335)

(6.752)

(2.333)

Constant

$-1,006^{* *}$

$-2,015$

$-3,888$ *

447.9*

(438.3)

$(1,259)$

$(2,072)$

(243.8)

\section{Observations}

1,368

243

203

922

R-squared

0.134

0.064

0.131

0.050

Note: Huber-White Robust standard errors in parentheses. One asterisk indicates significance at $10 \%$ level, two asterisks $5 \%$ level, three asterisks $1 \%$ level. 
Table 4b: OLS Regressions - Log of Pay vs Expected Sentence Exposure

\begin{tabular}{lcccc}
\hline & (1) - All Drugs & (2) - Cocaine & (3) - Meth & (4) - Marj \\
\hline & & & & \\
Total Quantity & $0.0188^{* * *}$ & -0.0154 & $-0.160^{* *}$ & $0.0228^{* * *}$ \\
& $(0.00472)$ & $(0.0405)$ & $(0.0679)$ & $(0.00498)$ \\
Total Quantity Squared & $-0.000225^{* * *}$ & 0.000279 & $0.00554^{* *}$ & $-0.000120^{* *}$ \\
& $(3.75 \mathrm{e}-05)$ & $(0.000781)$ & $(0.00245)$ & $(4.87 \mathrm{e}-05)$ \\
Expected Sentence Exposure & $0.608^{* * *}$ & $0.746^{* *}$ & $1.728^{* * *}$ & -0.330 \\
& $(0.100)$ & $(0.312)$ & $(0.341)$ & $(0.332)$ \\
Meth Load & $-0.748^{* * *}$ & & & \\
Marijuana Load & $(0.151)$ & & & \\
Time & $1.288^{* * *}$ & & & \\
& $(0.337)$ & & & \\
Constant & $0.00442^{* * *}$ & 0.00377 & -0.00337 & $0.00642^{* * *}$ \\
& $(0.00141)$ & $(0.00296)$ & $(0.00362)$ & $(0.00177)$ \\
& $4.819 * * *$ & $4.771^{* * *}$ & 0.0890 & $6.407^{* * *}$ \\
\hline Observations & $(0.338)$ & $(0.766)$ & $(1.316)$ & $(0.159)$ \\
R-squared & & & & \\
\hline Note: Hubs & 1,376 & 243 & 211 & 922 \\
& 0.151 & 0.172 & 0.329 & 0.063 \\
\hline
\end{tabular}

Note: Huber-White Robust standard errors in parentheses. One asterisk indicates significance at $10 \%$ level, two asterisks $5 \%$ level, three asterisks $1 \%$ level. 
Figure 5a: Estimated Load Value and Pay - Cocaine (Zero Order Polynomial Local Smoothing)

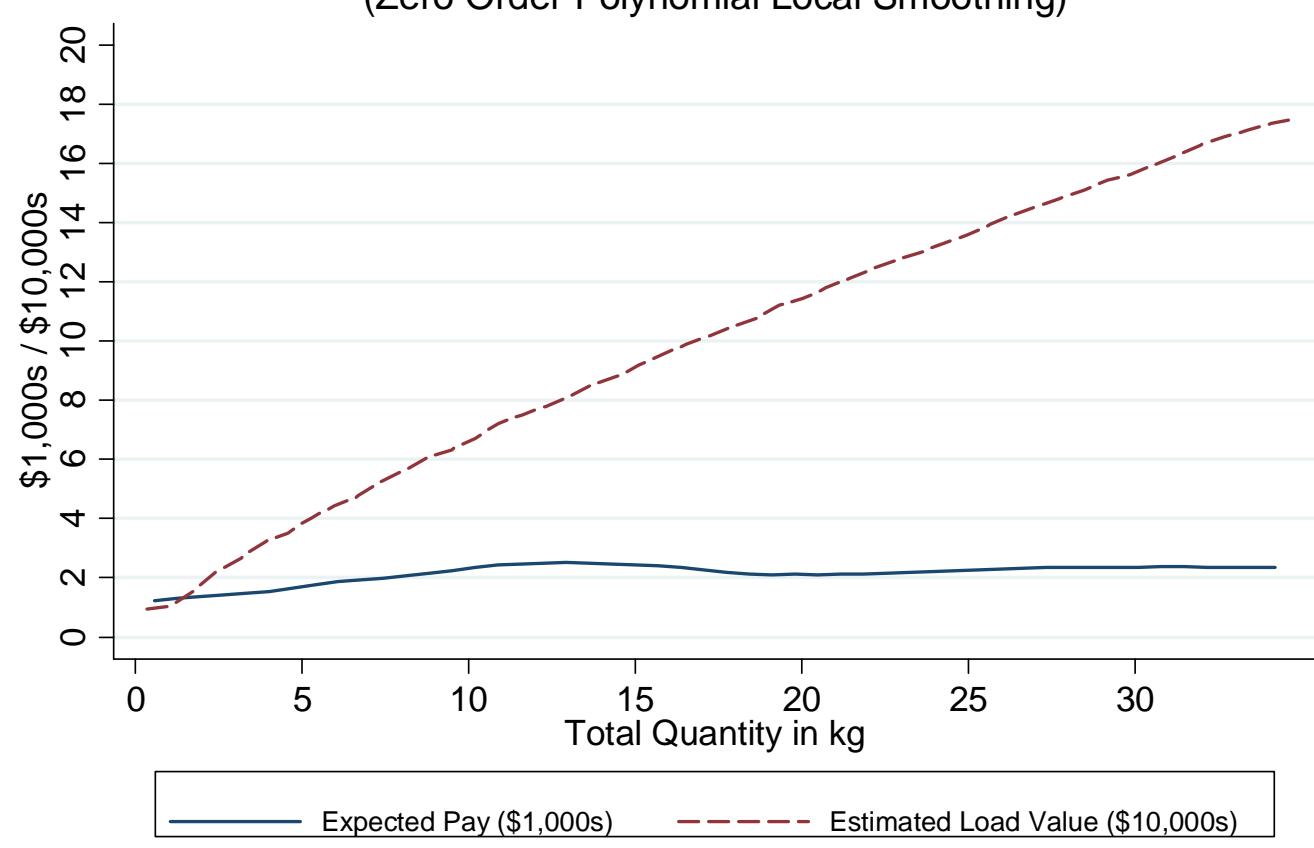

Figure 5b: Estimated Load Value and Pay - Marijuana (Zero Order Polynomial Local Smoothing)

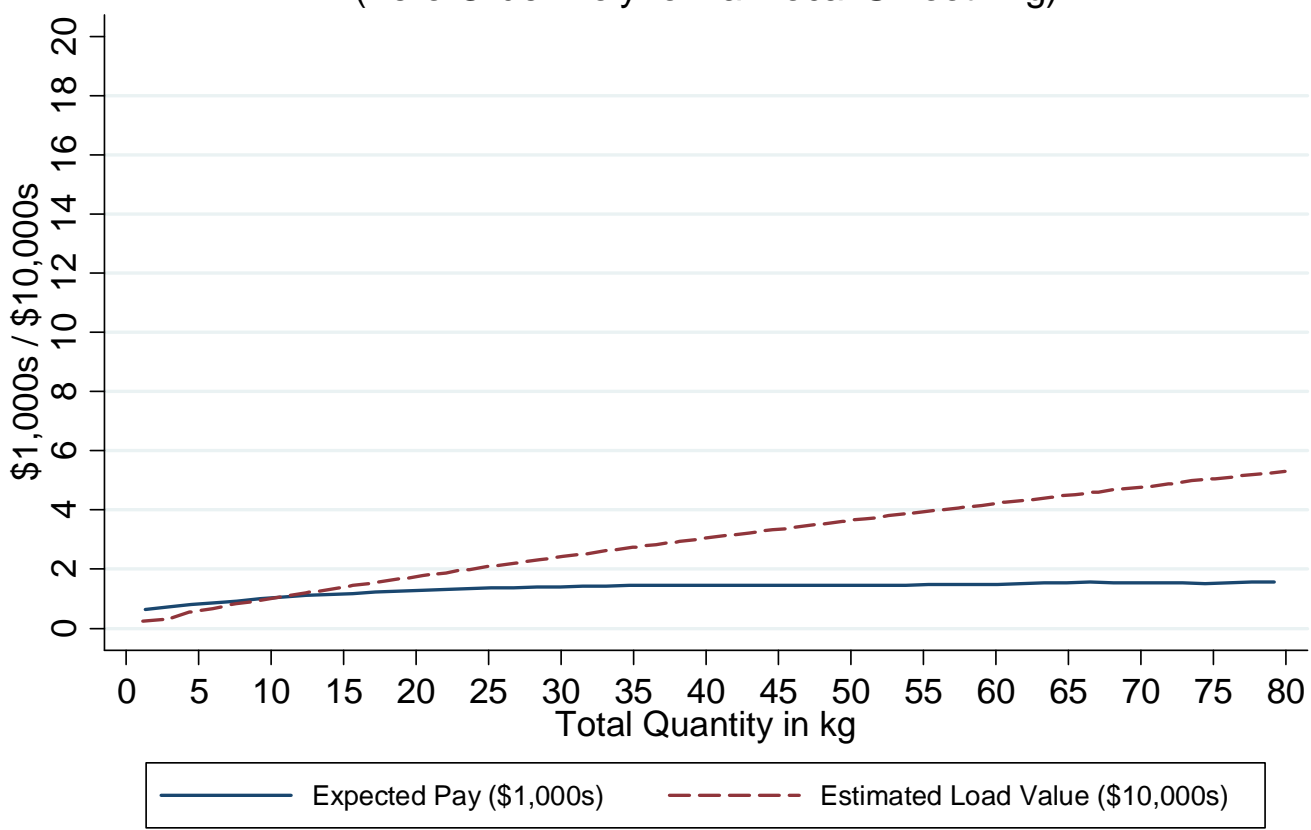


Table 5: OLS Regressions - Pay vs Other Characteristics

\begin{tabular}{|c|c|c|c|c|}
\hline & \multicolumn{2}{|c|}{ Dep Var: Pay } & \multicolumn{2}{|c|}{ Dep Var: In Pay } \\
\hline & (1) & (2) & (3) & (4) \\
\hline Total Quantity & $\begin{array}{c}17.20 * * * \\
(5.284)\end{array}$ & $\begin{array}{c}17.13^{* * *} \\
(5.289)\end{array}$ & $\begin{array}{c}0.0188 * * * \\
(0.00472)\end{array}$ & $\begin{array}{c}0.0184 * * * \\
(0.00471)\end{array}$ \\
\hline Total Quantity Squared & $\begin{array}{c}-0.237^{* * *} \\
(0.0525)\end{array}$ & $\begin{array}{c}-0.239 * * * \\
(0.0522)\end{array}$ & $\begin{array}{c}0.000225^{* * *} \\
(3.75 e-05)\end{array}$ & $\begin{array}{c}-0.000224 * * * \\
(3.75 e-05)\end{array}$ \\
\hline Expected Sentence Exposure & $\begin{array}{c}815.4 * * * \\
(120.5)\end{array}$ & $\begin{array}{c}824.5^{* * *} \\
(120.8)\end{array}$ & $\begin{array}{c}0.608^{* * *} \\
(0.100)\end{array}$ & $\begin{array}{c}0.617^{* * * *} \\
(0.101)\end{array}$ \\
\hline Meth Load & $\begin{array}{c}-1,113^{* * *} \\
(179.8)\end{array}$ & $\begin{array}{c}-1,103 * * * \\
(179.9)\end{array}$ & $\begin{array}{c}-0.748^{* * *} \\
(0.151)\end{array}$ & $\begin{array}{c}-0.755^{* * *} \\
(0.152)\end{array}$ \\
\hline Marijuana Load & $\begin{array}{c}1,572 * * * \\
(391.0)\end{array}$ & $\begin{array}{c}1,603 * * * \\
(391.8)\end{array}$ & $\begin{array}{c}1.288^{* * *} \\
(0.337)\end{array}$ & $\begin{array}{c}1.314^{* * *} \\
(0.339)\end{array}$ \\
\hline Female & & $\begin{array}{c}59.60 \\
(82.35)\end{array}$ & & $\begin{array}{c}0.0137 \\
(0.0467)\end{array}$ \\
\hline U.S. Citizen & & $\begin{array}{l}-39.39 \\
(109.0)\end{array}$ & & $\begin{array}{l}0.00983 \\
(0.0696)\end{array}$ \\
\hline Citizenship Missing & & $\begin{array}{l}-41.08 \\
(84.27)\end{array}$ & & $\begin{array}{l}0.00504 \\
(0.0516)\end{array}$ \\
\hline Time & $\begin{array}{c}8.275^{* * *} \\
(2.234)\end{array}$ & $\begin{array}{c}7.432 * * * \\
(2.322)\end{array}$ & $\begin{array}{c}0.00442 * * * \\
(0.00141)\end{array}$ & $\begin{array}{c}0.00401 * * * \\
(0.00150)\end{array}$ \\
\hline Constant & $\begin{array}{c}-1,303 * * * \\
(456.7)\end{array}$ & $\begin{array}{c}-1,241^{* *} \\
(513.7)\end{array}$ & $\begin{array}{c}4.819 * * * \\
(0.338)\end{array}$ & $\begin{array}{c}4.803^{* * *} \\
(0.350)\end{array}$ \\
\hline Month and Weekend Fixed Effects & no & yes & no & yes \\
\hline Observations & 1,376 & 1,376 & 1,376 & 1,376 \\
\hline R-squared & 0.136 & 0.145 & 0.151 & 0.161 \\
\hline
\end{tabular}

Note: Huber-White Robust standard errors in parentheses. Coefficients on month dummies and a dummy for a weekend arrest are not shown (none were statistically significant). One asterisk indicates significance at $10 \%$ level, two asterisks $5 \%$ level, three asterisks $1 \%$ level. 
Table 6: Comparing to those with Missing Pay Data

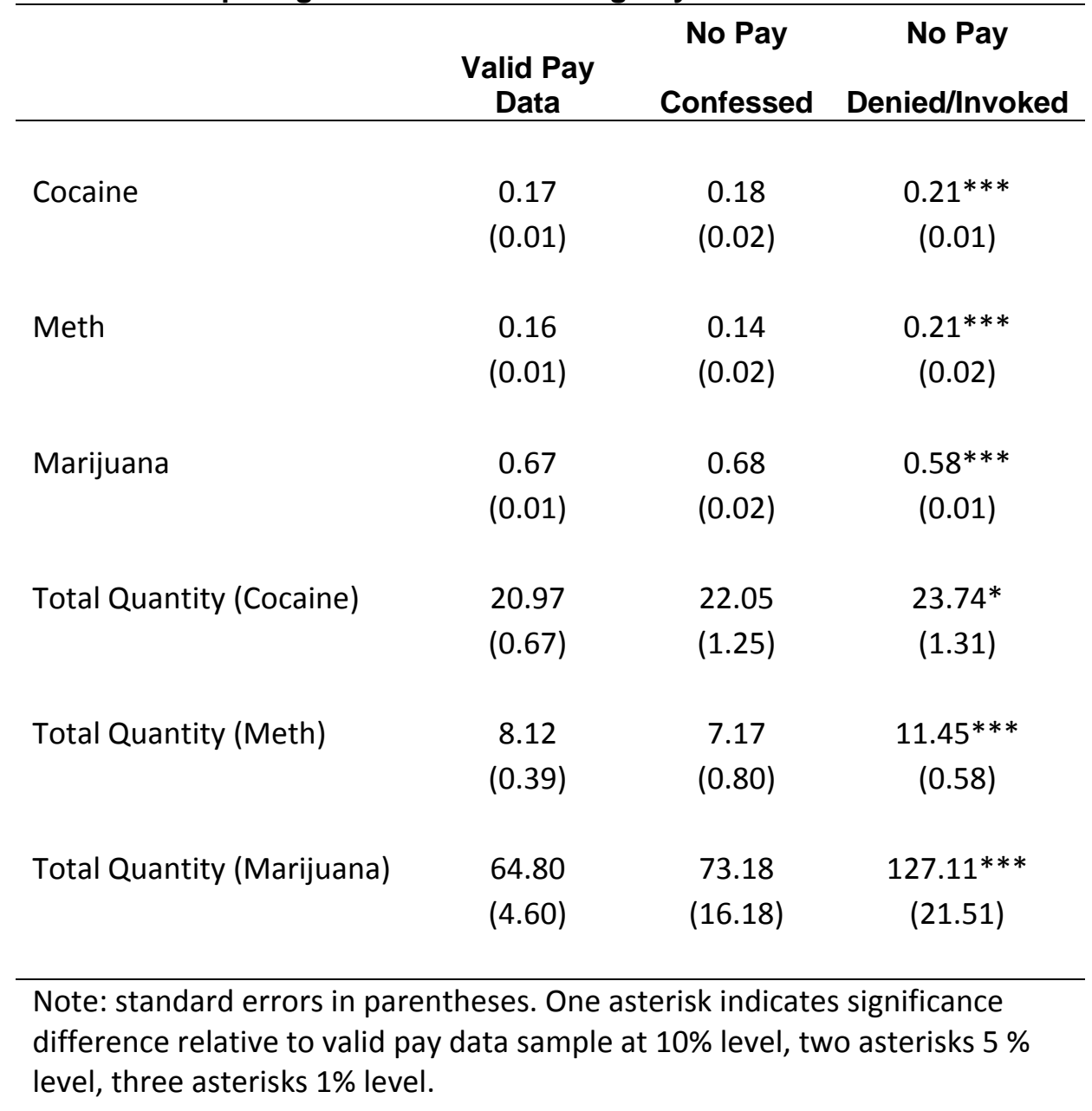


Table 7 - Criminal History Category

for "Matched Cases"

Criminal History

\begin{tabular}{ccc} 
Category & & Fraction \\
\hline 1 & 0.82 \\
2 & 0.05 \\
3 & 0.07 \\
4 & 0.03 \\
5 & 0.01 \\
6 & 0.03 \\
\hline $\mathrm{n}=$ & 190 \\
\hline
\end{tabular}

